Preprint, for published version see: R. Mevel, K. Chatelain, G. Blanquart, J. E. Shepherd "An updated reaction model for the high-temperature pyrolysis and oxidation of acetaldehyde" Fuel 217, 226-239, 2018. https://doi.org/10.1016/j.fuel.2017.12.060

\title{
An Updated Reaction Model for the High-Temperature Pyrolysis and Oxidation of Acetaldehyde
}

\author{
R. Mével ${ }^{*, a, b}$, K. Chatelain ${ }^{\mathrm{c}}$, G. Blanquart ${ }^{\mathrm{d}}$, J.E. Shepherde \\ ${ }^{a}$ Center for Combustion Energy, Tsinghua University, Beijing 100084, China \\ ${ }^{b}$ Department of Automotive Engineering, Tsinghua University, Beijing 100084, China \\ ${ }^{c}$ ENSTA-ParisTech, Paris-Saclay University, Palaiseau, France \\ ${ }^{d}$ Mechanical Engineering Department, California Institute of Technology, Pasadena, CA, USA \\ ${ }^{e}$ Graduate Aerospace Laboratories, California Institute of Technology, Pasadena, CA, USA
}

\begin{abstract}
Oxygenated biofuels such as fatty acid methyl esters or ethanol are incorporated in larger and larger amounts into conventional hydrocarbon fuels for use in internal combustion and jet engines. The use of these alternative fuels, along with new engine technology, results in an increased production of toxic pollutants among which aldehydes are the most abundant. The present study focuses on the kinetic modeling of acetaldehyde pyrolysis and oxidation. Based on new ignition delay-time measurements obtained in shock tube and the data from the literature, a comprehensive validation database was assembled. Available kinetic parameters for the most important chemical reactions are reviewed and an updated reaction model is proposed. The new reaction model enables reproducing most of the trends observed experimentally and constitutes an overall improvement as compared to standard detailed chemical models including Aramco 2.0, CaltechMech, and JetSurf.

Key words: Acetaldehyde, Biofuels, Toxic pollutants, Kinetics modeling
\end{abstract}

${ }^{*}$ Corresponding author: mevel@mail.tsinghua.edu.cn 


\section{Introduction}

To face future fossil fuel shortage and increasingly stringent regulations, the addition of bio-fuels to conventional fossil fuels [1-6] is increasingly prevalent due to the reduction in $\mathrm{CO}_{2}$ emissions either from exhaust measurements in some conditions $[3,4]$ or from indirect emissions with well-to-wheel analysis [7]. Contrary to the beneficial impacts on $\mathrm{CO}_{2}$ emissions, biofuels impact on emissions presents high variability depending on engine technologies, driving cycles or the blending levels considered. In the case of unregulated pollutants, bio-gasoline and bio-diesel combustion tends to induce an increase of a variety of carbonyl compounds, mainly aldehydes [8-14], which are being considered for specific regulations in some regions [15-17] due to their high toxicity $[11,18,19]$. Among aldehyde emissions from internal combustion engines, formaldehyde, acetaldehyde, and acrolein emissions are the highest carbonyl emissions $[8,11,12,20]$. Acetaldehyde has an important implication on urban atmospheric chemistry and air quality since it has been demonstrated as the primary precursor of peroxy acetyl nitrate (PAN). PAN has an important impact on tropospheric ozone and hydroxyl radical production [21, 22].

Acetaldehyde have been extensively studied within the last century and a comprehensive review on the development of acetaldehyde decomposition mechanism has been recently made by Sivaramakrishnan et al. [23]. Nevertheless, most recent detailed reaction models have employed limited data sets for the validation of acetaldehyde kinetics. Aramco 2.0 [24] has been compared to flow reactor and shock tube data, see supplemental material of [25]. CaltechMech [26] was validated against flame speed data. As for JetSurf, no specific validation is known to the authors but it was evaluated against flame structure data by Tao et al. [27]. Note that Aramco 1.3 was also employed by Tao et al. The most recent pyrolysis model for acetaldehyde developed by Sivaramakrishnan et al. [23] employs only two sets of experimental data from Vasiliou et al. [28, 29] and Kern et al. [30].

The present study aims at developing an updated and accurate detailed reaction model to describe the kinetics of acetaldehyde pyrolysis and oxidation over a wide range of conditions. Given the large number of experimental data available in the literature, we focused only on the high-temperature conditions typically obtained in 
shock-tube. Comparisons with other combustion relevant data (jet-stirred reactor, flame speed and structure) are provided as supplemental material. A comprehensive experimental data set, which covers wide ranges of compositions, conditions, and kinetics targets, has been assembled, based on the literature and new experimental work presently performed, to evaluate the predictive capabilities of the updated model and perform a comparison with selected state-of-the-art reaction models.

\section{Experimental method and results}

\subsection{Experimental method}

All gases were of research grade (Air Liquide). A mixture containing $2 \%$ by volume of acetaldehyde in argon was used to prepare the blends. Homogeneity of the mixtures was obtained by active mixing for one hour in a 9.25 liter vessel. Mixture compositions and experimental conditions are summarized in Table 1 (mixtures 1-3).

The shock-tube employed in the present study has been described in [31-33]. A three-section shock tube was employed to study the ignition of the acetaldehydeoxygen-argon mixtures. The driver and driven sections have an inner diameter of $15.24 \mathrm{~cm}$ and respective lengths of 6.19 and $11.28 \mathrm{~m}$. The test section is $2.44 \mathrm{~m}$ in length and has an inner diameter of $7.62 \mathrm{~cm}$. A cookie-cutter $(2.03 \mathrm{~m}$ in length with inner diameter of $7.62 \mathrm{~cm}$ ) enables to transmit the shock wave from the driven to the test section. Before each experiment, the test section was vacuumed to a pressure equal or below $1 \mathrm{~Pa}$. Nitrogen was used as the driver gas. The chemical dynamics of the mixtures was characterized using three simultaneous emission diagnostics: $\mathrm{OH}^{*}, \mathrm{CH}^{*}$ and $\mathrm{CO}_{2}{ }^{*}$. Recording the signals of these three species is interesting for kinetic modeling because their precursors are different $[31,33]$. The time to emission peak, $\tau_{100 \%}$, was used as a characteristic time of reaction for each species. The 1D shock theory along with the incident shock velocity were used to calculate the thermodynamic conditions behind the reflected shock wave. As in our previous studies, the uncertainties on the temperature and pressure behind the reflected shock are $1 \%$ whereas the uncertainty on $\tau_{100 \%}$ is of $20 \%$. Figure 1 a) shows a typical example of emission profiles and pressure signals obtained during the present study. 
Table 1: Compositions and conditions used during the experimental studies selected as a validation database. For mixture 12 and 13 , the equivalence ratio is defined using the $\mathrm{H}_{2}$ to $\mathrm{O}_{2}$ ratio. For all mixtures, the diluant used was argon except for mixtures 25 for which Neon was used, and mixtures 26 to 28 for which krypton was used.

\begin{tabular}{|c|c|c|c|c|c|c|c|c|}
\hline Mix & $\mathrm{X}_{\mathrm{CH} 3 \mathrm{CHO}}$ & $\mathrm{X}_{i}$ & $\mathrm{X}_{\mathrm{O} 2}$ & $\Phi$ & $\mathrm{T}_{5}(\mathrm{~K})$ & $\mathrm{P}_{5}(\mathrm{kPa})$ & Experimental target & Ref \\
\hline 1 & 0.005 & - & 0.025 & 0.50 & $1295-1537$ & $328-392$ & $\mathrm{OH}^{*}, \mathrm{CH}^{*}, \mathrm{CO}_{2} *$ & Present study \\
\hline 2 & 0.0086 & - & 0.0214 & 1.00 & $1370-1487$ & $316-404$ & $\mathrm{OH}^{*}, \mathrm{CH}^{*}, \mathrm{CO}_{2}{ }^{*}$ & Present study \\
\hline 3 & 0.0112 & - & 0.0187 & 1.50 & $1338-1580$ & $306-358$ & $\mathrm{OH}^{*}, \mathrm{CH}^{*}, \mathrm{CO}_{2}{ }^{*}$ & Present study \\
\hline 4 & 0.005 & - & 0.025 & 0.50 & $1313-1590$ & 353 & $\mathrm{CO}_{2}{ }^{*}$ & {$[34]$} \\
\hline 5 & 0.01 & - & 0.0125 & 2.00 & $1362-1734$ & 353 & $\mathrm{CO}_{2}^{*}$ & {$[34]$} \\
\hline 6 & 0.01 & - & 0.025 & 1.00 & $1252-1475$ & 505 & $\mathrm{CO}_{2}^{*}$ & {$[34]$} \\
\hline 7 & 0.005 & - & 0.025 & 0.50 & $1274-1515$ & 505 & $\mathrm{CO}_{2} *$ & {$[34]$} \\
\hline 8 & 0.01 & - & 0.05 & 0.50 & $1276-1530$ & 505 & $\mathrm{CO}_{2}{ }^{*}$ & {$[34]$} \\
\hline 9 & 0.025 & - & 0.025 & 2.50 & $1485-1674$ & $29-46$ & $\mathrm{O}_{2}$ & {$[35]$} \\
\hline 10 & 0.01 & - & 0.025 & 1.00 & $1404-1671$ & $29-53$ & $\mathrm{O}_{2}$ & {$[35]$} \\
\hline 11 & 0.01 & - & 0.035 & 0.71 & $1396-1631$ & $33-54$ & $\mathrm{O}_{2}$ & {$[35]$} \\
\hline 12 & & $\mathrm{X}_{H 2}=0.01$ & 0.01 & 0.50 & $1252-1731$ & 202 & $\mathrm{OH}$ & {$[36]$} \\
\hline 13 & 0.001 & $\mathrm{X}_{H 2}=0.01$ & 0.01 & 0.50 & $1280-1677$ & $148-227$ & $\mathrm{OH}$ & {$[36]$} \\
\hline 14 & 0.02 & - & 0.02 & 2.50 & $1400-1700$ & $197-270$ & $\mathrm{CO}_{2}, \operatorname{Abs}(216 \mathrm{~nm})$ & {$[36]$} \\
\hline
\end{tabular}




\begin{tabular}{cllcccccc} 
Mix & $\mathrm{X}_{\text {СH3CHO }}$ & $\mathrm{X}_{i}$ & $\mathrm{X}_{O 2}$ & $\Phi$ & $\mathrm{T}_{5}(\mathrm{~K})$ & $\mathrm{P}_{5}(\mathrm{kPa})$ & Experimental target & Ref \\
\hline 15 & 0.02 & - & 0.05 & 1.00 & $1280-1620$ & $173-258$ & $\mathrm{CO}_{2}$ & {$[36]$} \\
16 & 0.01 & - & 0.05 & 0.50 & $1300-1570$ & $169-229$ & $\mathrm{CO}_{2}$ & {$[36]$} \\
17 & 0.04 & - & 0.03 & 3.33 & $1393-1560$ & $224-272$ & $\mathrm{Abs}(3.39 \mu \mathrm{m}), \mathrm{Em}(4.68 \mu \mathrm{m})$ & {$[36]$} \\
18 & 0.05 & - & - & $\infty$ & $1013-1577$ & $128-286$ & $\mathrm{CH}_{3} \mathrm{CHO}, \mathrm{CO}, \mathrm{CH}_{4}, \mathrm{C}_{2} \mathrm{H}_{6}, \mathrm{C}_{2} \mathrm{H}_{4}, \mathrm{C}_{2} \mathrm{H}_{2}$ & {$[36]$} \\
19 & 0.04 & - & - & $\infty$ & $1329-1589$ & $200-272$ & $\mathrm{Abs}(3.39 \mu \mathrm{m}), \mathrm{Abs}(200 \mathrm{~nm}), \mathrm{Em}(4.68 \mu \mathrm{m})$ & {$[36]$} \\
20 & 0.01 & - & - & $\infty$ & $1278-1606$ & $169-188$ & $\mathrm{CH}_{3} \mathrm{CHO}$ & {$[37]$} \\
21 & $5.75 \mathrm{E}-06$ & - & - & $\infty$ & 1400 & 143 & $\mathrm{H}$ & {$[38]$} \\
22 & $6.39 \mathrm{E}-06$ & - & - & $\infty$ & 1440 & 123 & $\mathrm{H}$ & {$[38]$} \\
23 & $1.32 \mathrm{E}-06$ & - & - & $\infty$ & 1600 & 133 & $\mathrm{H}$ & {$[38]$} \\
24 & $2.62 \mathrm{E}-05$ & $\mathrm{X}_{C 2 H 5 I}=2.86 \mathrm{E}-6$ & - & $\infty$ & 1190 & 142 & $\mathrm{H}$ & {$[38]$} \\
25 & 0.032 & - & - & $\infty$ & 1717 & 32 & $\mathrm{CH}_{3} \mathrm{CHO}, \mathrm{CO}, \mathrm{CH}{ }_{4}, \mathrm{C}_{2} \mathrm{H}_{4}, \mathrm{C}_{2} \mathrm{H}_{2}$ & {$[30]$} \\
26 & $7.34 \mathrm{E}-07$ & - & - & $\infty$ & 1601 & 25 & $\mathrm{H}$ & {$[39]$} \\
27 & $1.19 \mathrm{E}-05$ & - & - & $\infty$ & 1314 & 50 & $\mathrm{H}$ & {$[39]$} \\
28 & $1.19 \mathrm{E}-04$ & $\mathrm{X}_{C 2 H 5 I}=1.06 \mathrm{E}-6$ & - & $\infty$ & 1085 & 35 & $\mathrm{CO}$ & {$[39]$} \\
29 & 0.001 & - & - & $\infty$ & 1447 & 162 & $\mathrm{CO}$ & {$[40]$} \\
30 & $5.00 \mathrm{E}-05$ & - & - & $\infty$ & 1494 & 151 & {$[40]$}
\end{tabular}




\subsection{Experimental results}

The emission of $\mathrm{OH}^{*}, \mathrm{CH}^{*}$ and $\mathrm{CO}_{2}{ }^{*}$ has been used to characterize the autoignition in acetaldehyde-based mixtures. Experiments were performed behind reflected shock wave with the parameter ranges: $\Phi=0.5-1.5 ; \mathrm{T}_{5}=1295-1580 \mathrm{~K}$; and $\mathrm{P}_{5}=306-392 \mathrm{kPa}$. The tabulated results are given as a supplemental material. As seen in Figure $1 \mathrm{a}), \mathrm{OH}^{*}$ and $\mathrm{CH}^{*}$ peak at a similar time whereas $\mathrm{CO}_{2}{ }^{*}$ peaks a few $\mu$ s later. The delay-times obtained with the different species are on average within $12 \%$ to each other, which is well below the estimated $20 \%$ uncertainty of the experimental values.

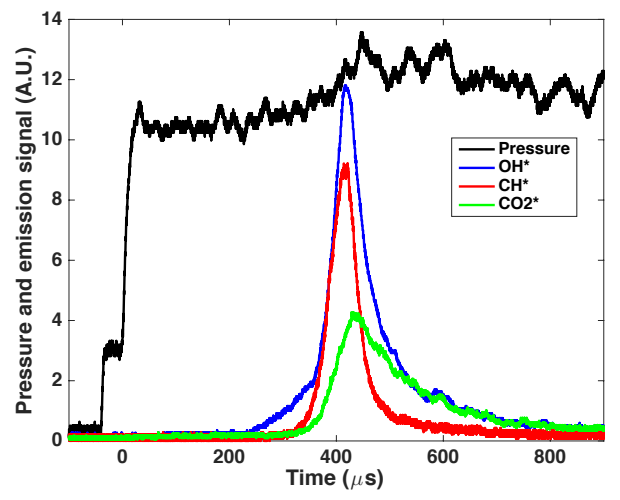

a) Experimental signals

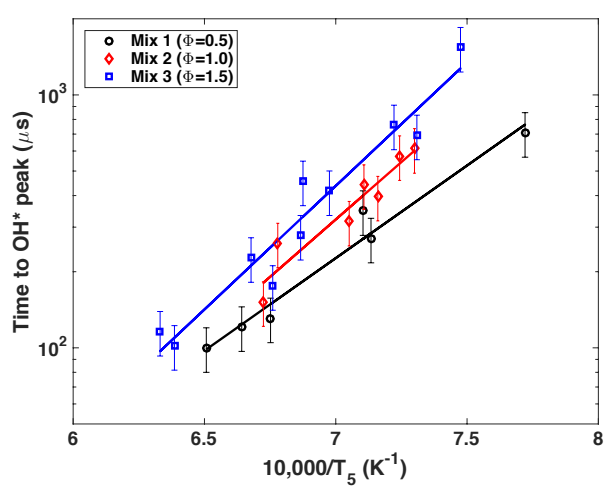

b) Characteristic time of reaction

Figure 1: a) Typical experimental pressure and emission signals during the auto-ignition of a rich $\mathrm{CH}_{3} \mathrm{CHO}-\mathrm{O}_{2}-\mathrm{Ar}$ mixture. Conditions: $\Phi=1.5 ; \mathrm{X}_{A r}=0.97 ; \mathrm{T}_{5}=1434 \mathrm{~K} ; \mathrm{P}_{5}=340 \mathrm{kPa}$. b) Characteristic time of reaction for some $\mathrm{CH}_{3} \mathrm{CHO}_{-} \mathrm{O}_{2}$ - $\mathrm{Ar}$ mixtures. Conditions: $\mathrm{X}_{A r}=0.97 ; \mathrm{P}_{5} \approx 350$ $\mathrm{kPa}$.

Figure $1 \mathrm{~b}$ ) shows the time to $\mathrm{OH}^{*}$ peak measured at three different equivalence ratios. As previously observed for acrolein [33] and numerous other fuels [41-46], the ignition delay-time decreases with decreasing equivalence ratio in this hightemperature range. This decrease is generally attributed to the enhancement of the chain branching process induced by the increase of oxygen concentration [33]. The ratio of the delay-times for the rich and the lean mixtures is between 2 and 2.8 for temperatures up to $1500 \mathrm{~K}$.

Based on the time to $\mathrm{OH}^{*}$ peak, the effective activation energy is $159 \mathrm{~kJ} / \mathrm{mol}$ $(\mathrm{P}=300-400 \mathrm{kPa})$ and is quantitatively consistent with the activation energy ex- 
tracted from Dagaut's data [34] for acetaldehyde, $154 \mathrm{~kJ} / \mathrm{mol}(\mathrm{P}=350-500 \mathrm{kPa})$. The activation energy for $\mathrm{CH}_{3} \mathrm{CHO}-\mathrm{O}_{2}$ - $\mathrm{Ar}$ mixtures is significantly higher than the activation energy obtained for acrolein-oxygen-argon mixtures [33], $126 \mathrm{~kJ} / \mathrm{mol}(\mathrm{P}=170$ $420 \mathrm{kPa}$ ). It agrees with the value reported by Zhang et al. [45], $166 \mathrm{~kJ} / \mathrm{mol}$ for butanal ( $\mathrm{P}=120-1000 \mathrm{kPa})$, but is lower than the values of Davidson et al. [46], 180 $\mathrm{kJ} / \mathrm{mol}$ also for butanal $(\mathrm{P}=130-180 \mathrm{kPa})$, and Yasunaga et al. [36], $177 \mathrm{~kJ} / \mathrm{mol}$ for acetaldehyde $(\mathrm{P}=170-270 \mathrm{kPa})$. In the present and previous studies [33, 34, 45, 46], emission signals $\left(\mathrm{OH}^{*}\right.$ and $\left.\mathrm{CO}_{2}{ }^{*}\right)$ were used to derive the activation energy, whereas in Yasunaga et al. [36], it was obtained from $\mathrm{CO}_{2}$ profiles-based delay-time. Even though large discrepancies exist between the reported activation energies for various small and large n-alkanes [41, 43, 46, 47], the activation energy measured in the present study and that reported by Dagaut et al. and Yasunaga et al. for acetaldehyde are of the same order or slightly lower than that of n-alkanes.

\section{Validation database}

A large number of studies have been performed on acetaldehyde [30, 34-40, 4866]. In the present study, we have selected a subset of these studies to validate an updated reaction model with respect to a large variety of kinetic targets, over wide ranges of compositions and conditions.

The studies used for validations are the following, presented in chronological order. Hidaka and Suga [35] employed the shock-tube/mass spectrometry technique to measure the evolution of molecular oxygen in reflected shock heated $\mathrm{CH}_{3} \mathrm{CHO}-\mathrm{O}_{2}-\mathrm{Ar}$ mixtures. Kern et al. [30] measured the concentrations of $\mathrm{CH}_{3} \mathrm{CHO}, \mathrm{CO}, \mathrm{CH}_{4}, \mathrm{C}_{2} \mathrm{H}_{4}$, and $\mathrm{C}_{2} \mathrm{H}_{2}$ as a function of time using the shock-tube/mass spectrometry technique. Dagaut et al. [34] measured the ignition delay-time of $\mathrm{CH}_{3} \mathrm{CHO}-\mathrm{O}_{2}$-Ar mixtures by monitoring the emission of $\mathrm{CO}_{2}{ }^{*}$ at $366 \mathrm{~nm}$. Yasunaga et al. [36] employed a large variety of diagnostics to study the pyrolysis and oxidation of $\mathrm{CH}_{3} \mathrm{CHO}$ : UV absorption at 200, 216 and $307 \mathrm{~nm}$; IR absorption at $3.39 \mu \mathrm{m}$; IR emission at 4.24 $\mu m$ and $4.68 \mu m$; sampling-CG analysis of $\mathrm{CH}_{3} \mathrm{CHO}, \mathrm{CO}, \mathrm{CH}_{4}, \mathrm{C}_{2} \mathrm{H}_{6}, \mathrm{C}_{2} \mathrm{H}_{4}$, and $\mathrm{C}_{2} \mathrm{H}_{2}$. Bentz et al. [38] and Sivaramakrishnan et al. [39] measured the concentration of $\mathrm{H}$ atoms during the pyrolysis of acetaldehyde using the atomic resonance 
absorption spectroscopy technique. Wang et al. [37] measured the concentration of acetaldehyde in $\mathrm{CH}_{3} \mathrm{CHO}-\mathrm{Ar}$ mixtures using laser absorption. Wang et al. [40] monitored CO profiles during the pyrolysis of acetaldehyde using IR laser absorption spectroscopy.

Table 1 summarizes the compositions and conditions of the studies included in the validation database which also include the results presently obtained. Note that the studies of Beeley et al. [48] and of Won et al. [49] have not been included in the validation database because of large discrepancies found between these sets of data and the predictions of several reaction models as described in [67].

\section{Preliminary kinetics modeling and analyses}

To make a preliminary assessment of the predictive capability of reference reaction models and determine important reactions for acetaldehyde pyrolysis and oxidation, Aramco 2.0 has been employed. The choice of this reaction model is motivated by the specific validation performed for acetaldehyde in Metcalfe et al. [25]. Note that complementary modeling results and analyses performed with Aramco 2.0 are presented as a supplemental material.

\subsection{Characteristic time of reaction}

Figure $2 \mathrm{a}$ ) and b) present a comparison between the experimental results (present data and data from [35]) and the predictions of Aramco 2.0. The reaction model tends to over-estimates (90-100\% error, see Table 2) the characteristic time of reaction based on emission signals but quantitatively reproduce the characteristic time based on $\mathrm{O}_{2}$ with a $31 \%$ relative error.

Figure 2 c) and d) present sensitivity analyses performed under oxidative conditions. The analyses performed on temperature, $\mathrm{CO}_{2}{ }^{*}, \mathrm{CO}_{2}$, and $\mathrm{O}_{2}$ are consistent with each other and demonstrate the primary importance of acetaldehyde decomposition, $\mathrm{CH}_{3} \mathrm{CHO}(+\mathrm{M})=\mathrm{CH}_{3}+\mathrm{HCO}(+\mathrm{M})$, the branching reaction $\mathrm{H}+\mathrm{O}_{2}=\mathrm{OH}+\mathrm{O}$, and $\mathrm{CH}_{3} \mathrm{CHO}+\mathrm{H}=\mathrm{CH}_{3} \mathrm{CO}+\mathrm{H}_{2}$. The later reaction acts as a sink of $\mathrm{H}$ atom which would be otherwise formed by the rapid decomposition of HCO. The sensitivity analyses also show the importance of methyl radicals chemistry. 


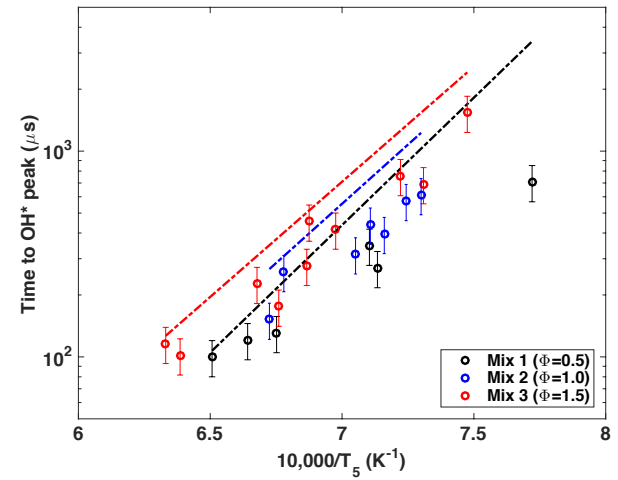

a) Present data

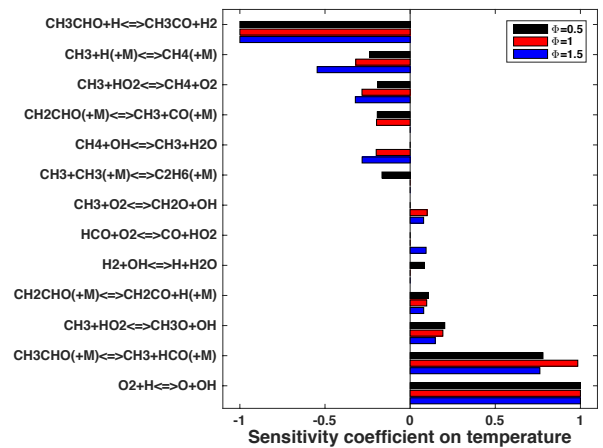

c) Sensitivity on temperature

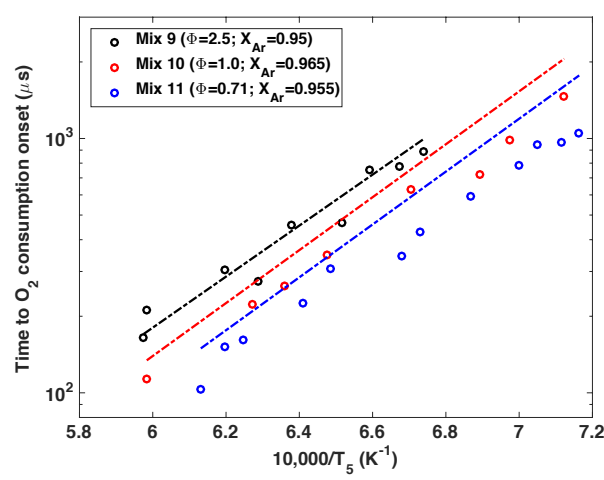

b) Data from Hidaka and Suga [35]

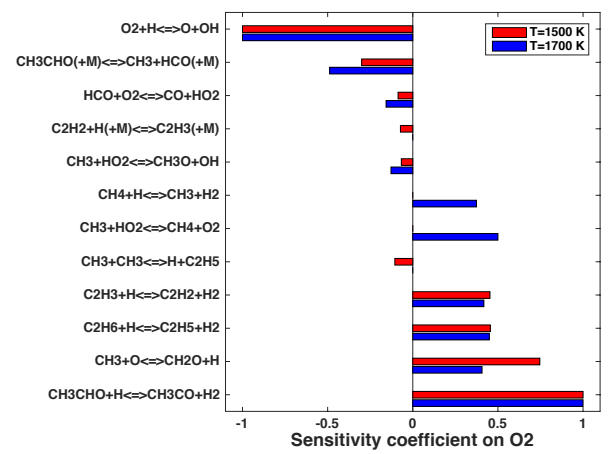

d) Sensitivity on $\mathrm{O}_{2}$

Figure 2: a) and b) Comparison between the experimental (present study and [35]) and the predicted (Aramco 2.0) ignition delay-time for $\mathrm{CH}_{3} \mathrm{CHO}-\mathrm{O}_{2}$-Ar mixtures. In a): $\mathrm{X}_{A r}=0.97 ; \mathrm{P}_{5} \approx 350$ $\mathrm{kPa}$. In b): $\mathrm{P}_{5} \approx 40 \mathrm{kPa}$. c) and d) Corresponding sensitivity analyses on temperature and $\mathrm{O}_{2}$. In c): mixture 1-3; $\mathrm{T}_{5}=1450 \mathrm{~K} ; \mathrm{P}_{5}=300 \mathrm{kPa}$. In d): mixture 9; $\mathrm{T}_{5}=1500$ and $1700 \mathrm{~K} ; \mathrm{P}_{5}=40 \mathrm{kPa}$.

\subsection{IR absorption and emission profiles}

In Figure 3 a) and b), the absorption and emission profiles have been calculated according to the procedure described in Yasunaga et al. [36]. Briefly, the absorption/emission profiles were calculated by including the contributions of the relevant species in each case, considering the concentrations predicted by the reaction models and the absorption/emission "cross-section" for each species provided by Yasunaga et al.. The absorption profiles were obtained considering the Beer-Lambert law while the emission profiles were obtained by simply summing up the contributions of all the emitting species. Since Figure 2 presents data obtained under oxidative conditions, only results obtained under pyrolytic conditions are provided.

In Figure 3 a), the experimental [36] and simulated absorption profiles at 3.39 
$\mu \mathrm{m}$ are displayed. This parameter is representative of the $\mathrm{C}-\mathrm{H}$ bond consumption rate. Overall, the predictions of Aramco 2.0 qualitatively and quantitatively match the experimental profiles.

In Figure $3 \mathrm{~b}$ ), the experimental and predicted emission profiles at $4.68 \mu \mathrm{m}$ are shown. This wavelength corresponds to a strong absorption/emission band of carbon monoxide [68]. However, Yasunaga et al. report that for the mixtures studied, the emission due to ketene, $\mathrm{CH}_{2} \mathrm{CO}$, plays a major role in reproducing the experimental profiles. Whereas Aramco 2.0 captures the shape of the profiles, discrepancies are observed in terms of amplitude.

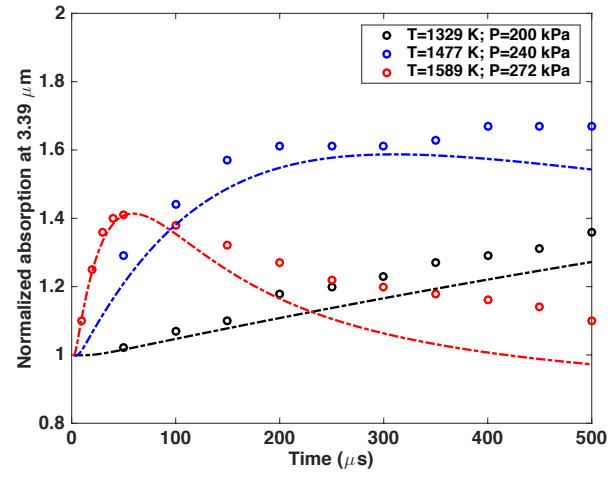

a) IR absorption

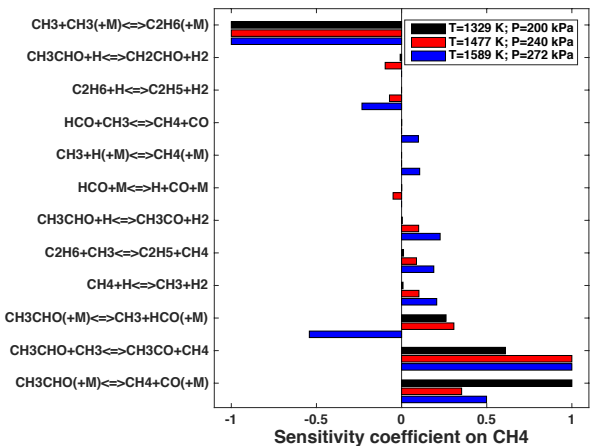

c) Sensitivity on $\mathrm{CH}_{4}$

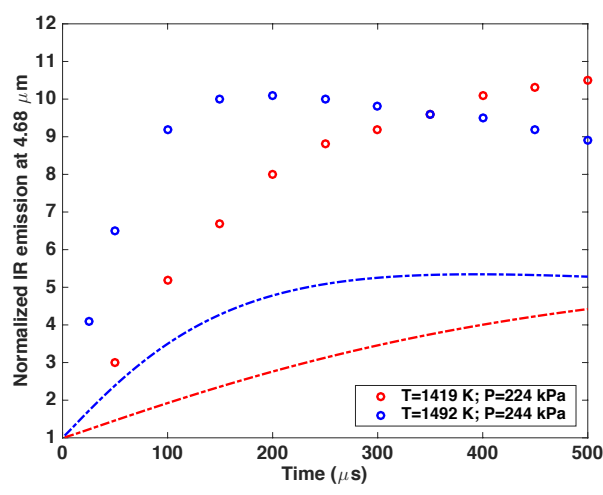

b) IR emission

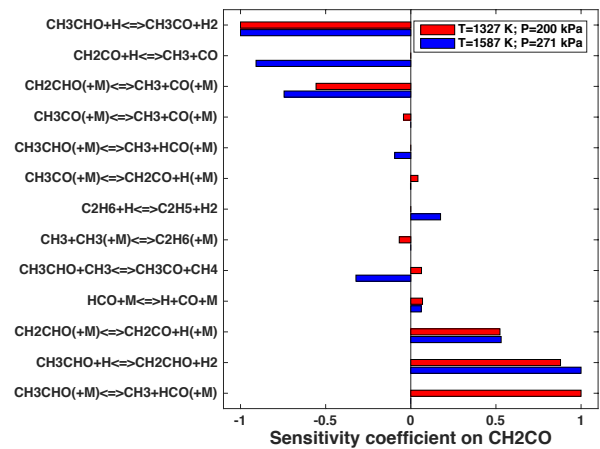

d) Sensitivity on $\mathrm{CH}_{2} \mathrm{CO}$

Figure 3: a) and b): Comparison between the experimental [36] and the predicted (Aramco 2.0) IR absorption/emission profiles during the pyrolysis of $\mathrm{CH}_{3} \mathrm{CHO}$. c) and d): Sensitivity analyses during the pyrolysis of $\mathrm{CH}_{3} \mathrm{CHO}$ performed with Aramco 2.0. For all figures, mixture $19(\Phi=\infty$; $\left.\mathrm{X}_{A r}=0.96\right)$ was considered.

Figure 3 c) and d) present sensitivity analyses performed for $\mathrm{CH}_{4}$ and $\mathrm{CH}_{2} \mathrm{O}$. These species have been selected due to their primary contribution to the IR ab- 
sorption/emission signals obtained by Yasunaga et al. [36]. These analyses confirm the important role of acetaldehyde decomposition and of the reactions of methyl radical, especially its recombination to form ethane. In addition, the importance of the $\mathrm{H}$-abstraction reactions (by $\mathrm{H}$ and $\mathrm{CH}_{3}$ ) on the methyl group of acetaldehyde, and their competition with the $\mathrm{H}$-abstraction reactions on the aldehyde group of $\mathrm{CH}_{3} \mathrm{CHO}$, are to be underlined. The IR emission signals are also sensitive to the decomposition of $\mathrm{CH}_{2} \mathrm{CHO}$ into $\mathrm{CH}_{2} \mathrm{CO}$ and $\mathrm{H}$.

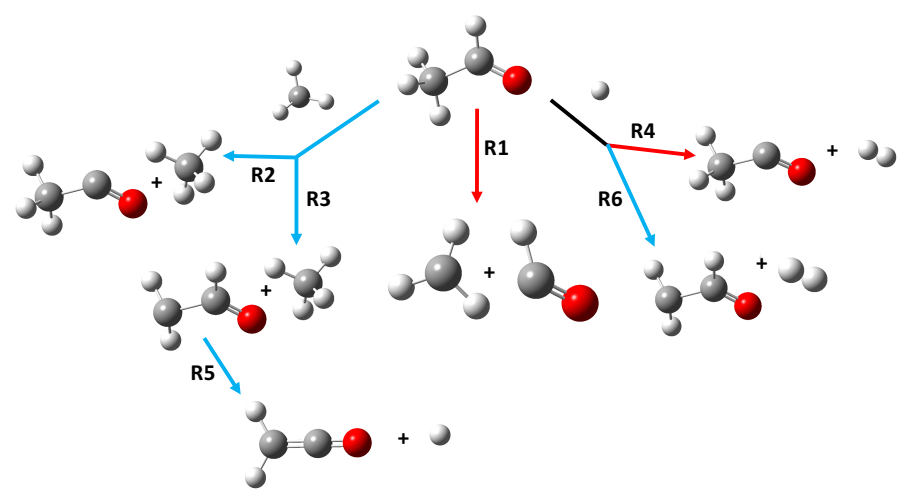

Figure 4: Summary of important reaction pathways during $\mathrm{CH}_{3} \mathrm{CHO}$ pyrolysis and oxidation. The red arrows indicate important pathways for $\mathrm{CH}_{3} \mathrm{CHO}$ oxidation whereas the blue arrows indicate important pathways for the formation of $\mathrm{CO}$ and $\mathrm{CH}_{2} \mathrm{CO}$ under pyrolytic conditions.

\subsection{Summary of important reactions}

The different analyses we performed enabled to identify six reactions which control the ignition and speciation during $\mathrm{CH}_{3} \mathrm{CHO}$ pyrolysis and oxidation:

- $\mathrm{R}_{1}: \mathrm{CH}_{3} \mathrm{CHO}=\mathrm{CH}_{3}+\mathrm{HCO}$

- $\mathrm{R}_{2}: \mathrm{CH}_{3} \mathrm{CHO}+\mathrm{CH}_{3}=\mathrm{CH}_{3} \mathrm{CO}+\mathrm{CH}_{4}$

- $\mathrm{R}_{3}: \mathrm{CH}_{3} \mathrm{CHO}+\mathrm{CH}_{3}=\mathrm{CH}_{2} \mathrm{CHO}+\mathrm{CH}_{4}$

- $\mathrm{R}_{4}: \mathrm{CH}_{3} \mathrm{CHO}+\mathrm{H}=\mathrm{CH}_{3} \mathrm{CO}+\mathrm{H}_{2}$

- $\mathrm{R}_{5}: \mathrm{CH}_{2} \mathrm{HCO}=\mathrm{CH}_{2} \mathrm{CO}+\mathrm{H}$

- $\mathrm{R}_{6}: \mathrm{CH}_{3} \mathrm{CHO}+\mathrm{H}=\mathrm{CH}_{2} \mathrm{CHO}+\mathrm{H}_{2}$ 
These important pathways are summarized in Figure 4. The importance of $R_{1}$ and $R_{4}$ to the oxidation process and of $R_{2}, R_{3}, R_{5}$ and $R_{6}$ to the pyrolysis process (formation of $\mathrm{CO}$ and $\mathrm{CH}_{2} \mathrm{CO}$, see previous subsection) are differentiated in Figure 4 with a color code.

Other important reactions such as $\mathrm{H}+\mathrm{O}_{2}=\mathrm{OH}+\mathrm{O}$ and $\mathrm{CH}_{3}+\mathrm{CH}_{3}(+\mathrm{M})=\mathrm{C}_{2} \mathrm{H}_{6}(+\mathrm{M})$ have been reviewed elsewhere [69-72] and will not be further discussed. The present results are consistent with a sensitivity analysis performed by Wang et al. [37] who identified reactions $R_{1}, R_{2}$, and $R_{4}$ as the most sensitive during acetaldehyde pyrolysis.

\section{Updated kinetic parameters}

\subsection{Decomposition of acetaldehyde}

A number of elementary reaction rate studies [38, 40, 73] have been performed over the past 10 years on the decomposition of $\mathrm{CH}_{3} \mathrm{CHO}$. We chose to employ these data obtained at pressure below $500 \mathrm{kPa}$, along with earlier data [65] obtained at high pressure, to propose updated kinetics parameters for the reaction $R_{1}$.

Ernst et al. [65] performed measurement behind reflected shock wave using absorption at $290 \mathrm{~nm}$ by $\mathrm{CH}_{3} \mathrm{CHO}$. The experiments were performed in the temperature range $1350-1650 \mathrm{~K}$ and at pressure up to $25 \mathrm{MPa}$. Gupte et al. [73] employed laser-schlieren measurement in incident shock heated mixtures over the ranges $\mathrm{T}_{2}=1530-2465 \mathrm{~K}$ and $\mathrm{P}_{2}=13-169 \mathrm{kPa}$. Bentz et al. [38] derived the rate constant for $\mathrm{R}_{1}$ using $\mathrm{H}$ atom resonant absorption spectroscopy in reflected shock heated mixtures for $\mathrm{T}_{5}=1270-1650 \mathrm{~K}$ and $\mathrm{P}_{5}=120-505 \mathrm{kPa}$. Wang et al. [40] used cavity enhanced absorption spectroscopy of $\mathrm{CO}$ over the ranges $\mathrm{T}_{5}=1273-1618 \mathrm{~K}$ and $\mathrm{P}_{5}=30-177 \mathrm{kPa}$. Because the measurements of Gupte have been performed in krypton, whereas Ernst, Bentz and Wang used argon, a temperature-dependent correction has been applied based on the collision efficiency calculations reported by Jasper et al. [74]. The correction is expressed as

$$
k_{A r}(T)=k_{K r}(T) / C o l_{K r}(T)
$$


with

$$
\operatorname{Col}_{K r}(T)=-0.000035294 \times T+0.97059
$$

assuming a linear variation of the collision efficiency with temperature. The maximum correction applied to the rate constant was $13 \%$.

In order to combine the data of the four studies (165 data points), a Troe formalism has been adopted. The high-pressure limit was taken from Harding et al. [75]. This approach which consists of combining experimental and theoretical rate constant values was previously adopted by Troe [76]. The updated low-pressure rate constant for Ar as the third body is expressed as

$$
k_{0}^{R_{1}}=9.56 \times 10^{82} \cdot T^{-18.1289} \cdot \exp \left(\frac{-53409}{T}\right) \mathrm{cm}^{3} \mathrm{~mol}^{-1} \mathrm{~s}^{-1}
$$

with centering parameters: $\alpha=0.6 ; T^{* *}=1 \mathrm{~K} ; T^{*}=1 \mathrm{~K} ; T^{* *}=3444.1 \mathrm{~K}$.

To assess the improvement introduced by the new expression we derived for $\mathrm{R}_{1}$, we performed a quantitative comparison of the rate constants used in the four reaction models tested (the present model, Aramco 2.0 [24], CaltechMech [26], and JetSurf [77]) with respect to the experimental data from Ernst et al. [65], Gupte et al. [73], Bentz et al. [38], and Wang et al. [40].

The relative error, $E_{i}$, of the $i^{\text {th }}$ data point was calculated using

$$
E_{i}=100 \frac{k_{\text {expe }}^{i}-k_{\text {model }}^{i}}{k_{\text {expe }}^{i}}
$$

where $k_{\text {expe }}^{i}$ and $k_{\text {model }}^{i}$ are respectively the rate constants measured and calculated for the $i^{\text {th }}$ data point.

For the new model, Aramco, CaltechMech and JetSurf, the mean errors are -2.9, $26.3,18.9$, and $84.1 \%$, respectively. The mean error, $\mu$, was calculated as follows:

$$
\mu=100 \frac{1}{N} \sum_{i=1}^{N} \frac{k_{\text {expe }}^{i}-k_{\text {model }}^{i}}{k_{\text {expe }}^{i}}
$$

where $\mathrm{N}$ is the number of experimental data points.

The corrected sample standard deviation, $\sigma$, was calculated using

$$
\sigma=\sqrt{\frac{1}{N-1} \sum_{i=1}^{N}\left(E_{i}-\mu\right)^{2}}
$$


and is respectively 24.6, 17.6, 17.5, and 9.2\% for the new model, Aramco, CaltechMech and JetSurf.

In addition, the probability density of error has been calculated considering bins of $5 \%$. The probability density, $P D_{j}$, for the $j^{\text {th }}$ bin is

$$
P D_{j}=\frac{n_{j}}{N}
$$

where $n_{j}$ is the number of data points for which

$$
E_{i}-\nu_{j}<2.5
$$

with $\nu_{j}$ the central value of the $j^{\text {th }}$ bin.

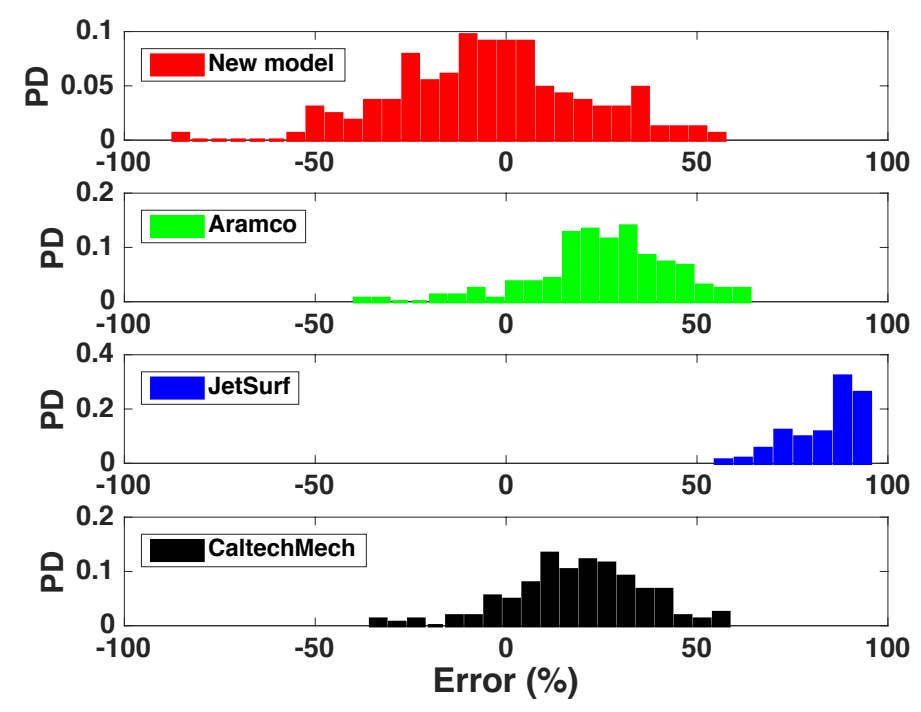

Figure 5: Probability density (PD) of error for the rate constants included in each model with respect to experimental measurements of $\mathrm{R}_{1}$ taken from [38, 40, 65, 73].

Figure 5 shows the results of this analysis. For the rate constants used in the new model, Aramco and CaltechMech, the distributions of probability density of error are normal (from $\chi^{2}$ test) whereas it is not the case for the rate constant used in JetSurf. Only the present rate constant demonstrates a distributions of probability density of error centered on 0 . The other rate constants exhibit distributions centered much above 0 which indicates an under-estimation of the experimental values.

The results presented in this section indicate that the updated rate constant proposed in the present study enables to better reproduce the experimental mea- 
surements performed in four independent studies with four different experimental techniques.

\subsection{Hydrogen abstraction}

The sensitivity and reaction pathway analyses performed in the previous section have shown that the hydrogen abstraction reactions $\mathrm{R}_{2}: \mathrm{CH}_{3} \mathrm{CHO}+\mathrm{CH}_{3}=\mathrm{CH}_{3} \mathrm{CO}+\mathrm{CH}_{4}$, $\mathrm{R}_{3}: \mathrm{CH}_{3} \mathrm{CHO}+\mathrm{CH}_{3}=\mathrm{CH}_{2} \mathrm{CHO}+\mathrm{CH}_{4}, \mathrm{R}_{4}: \mathrm{CH}_{3} \mathrm{CHO}+\mathrm{H}=\mathrm{CH}_{3} \mathrm{CO}+\mathrm{H}_{2}, \mathrm{R}_{6}: \mathrm{CH}_{3} \mathrm{CHO}$ $+\mathrm{H}=\mathrm{CH}_{2} \mathrm{CHO}+\mathrm{H}_{2}$ play an important role during the pyrolysis and oxidation of acetaldehyde. In the theoretical study of Mendes et al. [78], the rate constants for the $\mathrm{H}$-abstraction reaction of aldehydes and acids by various radicals have been calculated. The reaction rates included in the updated model are those given by Mendes et al. $[78]$

$$
\begin{gathered}
k^{R_{2}}=1.55 \times T^{3.70} \cdot \exp \left(\frac{-2295}{T}\right) \mathrm{cm}^{3} \mathrm{~mol}^{-1} \mathrm{~s}^{-1} \\
k^{R_{3}}=4.79 \times 10^{-01} \times T^{3.70} \cdot \exp \left(\frac{-4453}{T}\right) \mathrm{cm}^{3} \mathrm{~mol}^{-1} \mathrm{~s}^{-1} \\
k^{R_{4}}=6.90 \times 10^{05} \times T^{2.40} \cdot \exp \left(\frac{-958}{T}\right) \mathrm{cm}^{3} \mathrm{~mol}^{-1} \mathrm{~s}^{-1} \\
k^{R_{6}}=1.05 \times 10^{05} \times T^{2.50} \cdot \exp \left(\frac{-4043}{T}\right) \mathrm{cm}^{3} \mathrm{~mol}^{-1} \mathrm{~s}^{-1}
\end{gathered}
$$

These rate parameters have been shown to agree with previous experimental and theoretical studies and are accurate within a factor of 2.5. Consistent with the study of da Silva and Bozzelli [9], the H-abstraction on the aldehyde group strongly dominates over the abstraction on the methyl group with branching ratios above $90 \%$ over the temperature range 1000-2000 K.

\subsection{Reactions of ketene with hydrogen atoms}

Yasunaga et al. [36] demonstrated the importance of ketene's contribution to the emission and absorption profiles obtained in the IR and UV. Ketene was also identified as a product of the thermal decomposition of acetaldehyde in the micro-tubular reactor experiments of Vasiliou et al. [28]. In [67], sensitivity and rate of production analyses on $\mathrm{CH}_{2} \mathrm{CO}$ have demonstrated the importance of the decomposition reaction of formyl methyl radical to ketene and $\mathrm{H}$ atom: $\mathrm{R}_{5}: \mathrm{CH}_{2} \mathrm{HCO}=\mathrm{CH}_{2} \mathrm{CO}+\mathrm{H}$. Senosiain et al. [79] studied this reaction over a wide range of pressure using ab 
initio calculations. Note that Yasunaga et al. included in their reaction mechanism the reaction rate proposed by Senoniain for a pressure of $101 \mathrm{kPa}$. To avoid using a rate coefficient derived for a specific pressure and enable an easier comparison with other reaction rates, we considered the rate coefficients for the reverse reaction $R_{-5}$ $\mathrm{CH}_{2} \mathrm{CO}+\mathrm{H}=\mathrm{CH}_{2} \mathrm{CHO}$.

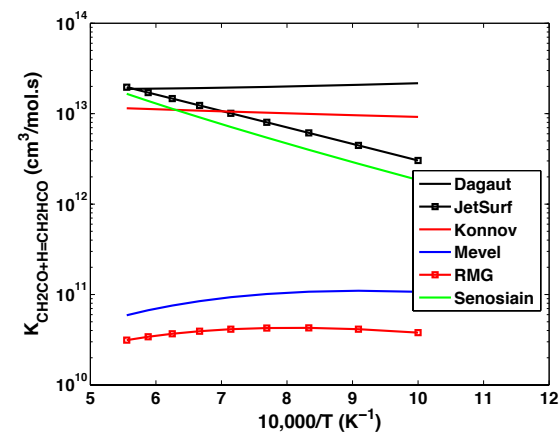

Figure 6: Available rate constants for the reaction $\mathrm{CH}_{2} \mathrm{CO}+\mathrm{H}=\mathrm{CH}_{2} \mathrm{CHO}$ [33, 67, 77, 79-82].

Figure 6 displays the high-pressure limit reaction rates available for this reaction. Very large discrepancies, more than two orders of magnitude, can be observed between the different reaction rates available in many reaction models [33, 67, 77, 8082] and the literature. Except for JetSurf, the reaction rates included in the reaction models exhibit a weak temperature dependence over the temperature range 1000-1800 K. The theoretical study of Senoniain et al. indicates that this reaction demonstrates a significant temperature dependence. Given the accuracy of quantum calculation on the transition state energy level [83] and reaction rate at high temperature [84], it is likely that the reaction rate of $\mathrm{CH}_{2} \mathrm{CO}+\mathrm{H}=\mathrm{CH}_{2} \mathrm{HCO}$ exhibits a temperature dependence and consequently, we chose to include the value of Senoniain et al.:

$$
k^{R_{-5}}=1.99 \times 10^{09} \times T^{1.43} \cdot \exp \left(\frac{-3045}{T}\right) \mathrm{cm}^{3} \mathrm{~mol}^{-1} \mathrm{~s}^{-1} .
$$

For consistency, we included the rate constants proposed by Senosiain et al. [79] for the other possible pathways for the reaction between $\mathrm{CH}_{2} \mathrm{CO}$ and $\mathrm{H}, \mathrm{R}_{7}: \mathrm{CH}_{2} \mathrm{CO}+\mathrm{H}=$ $\mathrm{CH}_{3} \mathrm{CO}$ and $\mathrm{R}_{8}: \mathrm{CH}_{2} \mathrm{CO}+\mathrm{H}=\mathrm{CH}_{3}+\mathrm{CO}$ :

$$
k^{R_{7}}=2.30 \times 10^{08} \times T^{1.61} \cdot \exp \left(\frac{-1322}{T}\right) \mathrm{cm}^{3} \mathrm{~mol}^{-1} \mathrm{~s}^{-1},
$$


and

$$
k^{R_{8}}=7.77 \times 10^{08} \times T^{1.45} \cdot \exp \left(\frac{-1399}{T}\right) \mathrm{cm}^{3} \mathrm{~mol}^{-1} \mathrm{~s}^{-1} .
$$

\subsection{Vinyl alcohol formation}

Vasiliou et al. [28, 29] studied the pyrolysis of acethaldehyde in a micro-tubular flow reactor using matrix infrared spectroscopy and photo-ionization mass spectrometry. Under these high-temperature (1200-1900 K), low-pressure (6.7-26.7 kPa), short-residence-time (50-200 $\mu \mathrm{s})$ conditions, they found that the formation of vinyl alcohol, through acetaldehyde isomerization: $\mathrm{CH}_{3} \mathrm{CHO}=\mathrm{CH}_{2} \mathrm{CHOH}$, was a primary consumption pathway after $\mathrm{CH}_{3} \mathrm{CHO}(+\mathrm{M})=\mathrm{CH}_{3}+\mathrm{HCO}(+\mathrm{M})$. For chemical consistency, 15 reactions describing the formation of vinyl alcohol and subsequent pathways have been included in our updated model based on the theoretical study of Sivaramakrishnan et al. [23].

\subsection{Reactions of excited $\mathrm{OH}^{*}, \mathrm{CH}^{*}$ and $\mathrm{CO}_{2}{ }^{*}$}

The reactions for $\mathrm{OH}^{*}$ and $\mathrm{CH}^{*}$ are the same as those included in our previous study on acrolein [33]. The reactions for $\mathrm{CO}_{2}{ }^{*}$ have been updated according to the recent study of Kopp et al. [85]. Reactions for $\mathrm{OH}^{*}, \mathrm{CH}^{*}$ and $\mathrm{CO}_{2}{ }^{*}$ have been included in the other reaction models tested in the present study to ensure that differences in the modeling results do not come from a difference in the excited species chemistry.

\subsection{Ethyl iodide sub-mechanism}

Since Bentz et al. [38] and Sivaramanakrishnam et al. [39] have employed ethyl iodide as a $\mathrm{H}$ atom precursor to study its consumption by acetaldehyde, a submechanism, which includes 11 reactions and 12 species, was added to the models presently tested to describe $\mathrm{C}_{2} \mathrm{H}_{5} \mathrm{I}$ high-temperature chemistry. The reaction rates were taken from the studies of Kumaran et al. [86, 87], Bentz et al. [88], Knox and Musgrave [89], Lifshitz et al. [90], Pardini and Martin [91], and Baulch et al. [92].

\section{Validation of the model}

This section presents a comparison between the experimental data and the predictions of four detailed reaction models: (i) the present updated model, (ii) Aramco 
2.0 [24], (iii) CaltechMech [26], and (iv) JetSurf [77]. The compositions and conditions are summarized in Table 1. In Figure 7 to Figure 11, the predictions of the present model are shown as solid lines, the predictions of the Aramco 2.0 are shown as dashed-dotted lines, the predictions of CaltechMech are shown as dotted lines, and the predictions of JetSurf are shown as dashed lines. Such a comparison enables benchmarking the performances of the present model with respect to state-of-theart reaction models. First, representative comparisons are shown for characteristic time of reaction (referred to as delay-times) obtained from different chemical species. Second, a number of representative time-resolved and temperature-resolved species profiles are used to make the comparison. For the calculations shown in the present and next sections, the modeling was performed using Cantera [93] with the constant volume reactor model. Additional comparisons are shown as a supplemental material.

\begin{tabular}{ccccccc} 
Mix & Present model & Aramco 2.0 & CaltechMech & JetSurf & Diagnostics & Ref \\
\hline $1-3$ & $45(42)$ & 96 & 73 & 159 & $\mathrm{OH}^{*}$ & Present study \\
$1-3$ & $49(46)$ & 102 & 79 & 168 & $\mathrm{CH}^{*}$ & Present study \\
$1-3$ & $45(42)$ & 92 & 71 & 153 & $\mathrm{CO}_{2}^{*}$ & Present study \\
$4-8$ & $58(55)$ & 119 & 91 & 186 & $\mathrm{CO}_{2}^{*}$ & {$[34]$} \\
$9-11$ & $11(13)$ & 31 & 14 & 67 & $\mathrm{O}_{2}$ & {$[35]$} \\
$12-13$ & $18(19)$ & 24 & 24 & 25 & $\mathrm{OH}^{*}$ & {$[36]$} \\
$14-16$ & $22(22)$ & 42 & 25 & 60 & $\mathrm{CO}_{2}$ & {$[36]$}
\end{tabular}

Table 2: Mean error (\%) between the prediction of the reaction models used in the present study and the experimental delay-times from the present study and [34-36]. The numbers indicated between parenthesis correspond to the error for the present reaction model without the sub-mechanism for vinyl alcohol chemistry.

\subsection{Delay-times}

The ability of the reaction models to predict the available delay-times has been quantified by calculating the mean error for each set of experimental data. The 

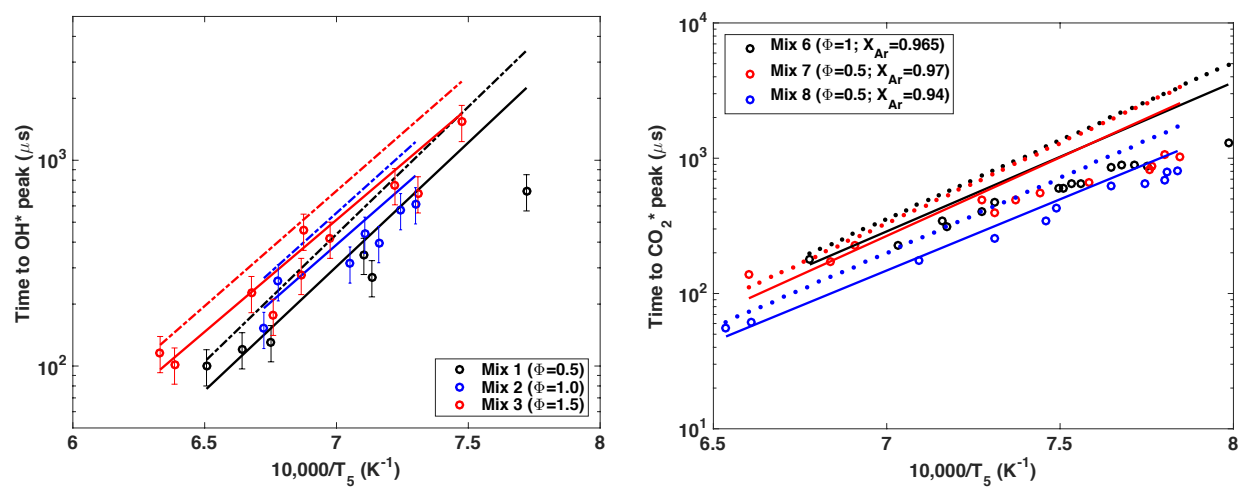

a) $\mathrm{OH}^{*}$ emission (Present study)

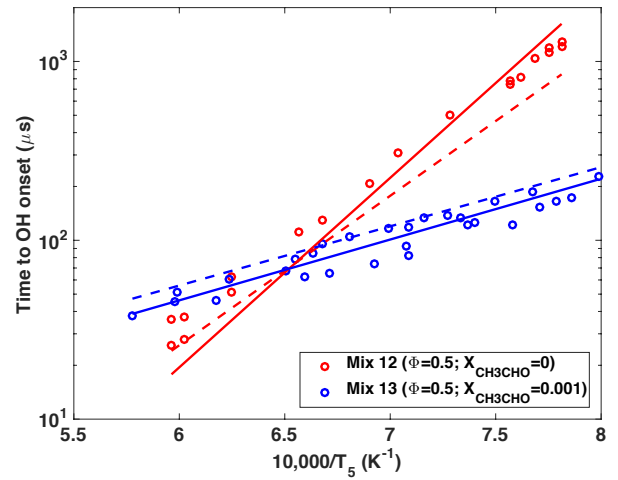

b) $\mathrm{CO}_{2} *$ emission [34]

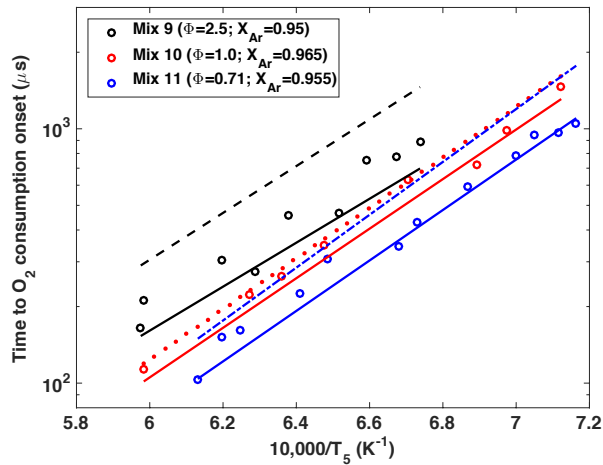

c) $\mathrm{OH}$ absorption $[36]$

d) $\mathrm{O}_{2}$ detected with $\mathrm{MS}$ [35]

Figure 7: Comparison between the experimental and calculated delay-time based on $\mathrm{OH}^{*}, \mathrm{CO}_{2}{ }^{*}$, $\mathrm{OH}$ and $\mathrm{O}_{2}$ for $\mathrm{CH}_{3} \mathrm{CHO}-\mathrm{O}_{2}$-Ar mixtures. In a): $\mathrm{X}_{A r}=0.97 ; \mathrm{P}_{5} \approx 350 \mathrm{kPa}$. In b): $\mathrm{P}_{5} \approx 500 \mathrm{kPa}$. In c): $\mathrm{X}_{A r}=0.98 ; \mathrm{P}_{5} \approx 200 \mathrm{kPa}$. In d): $\mathrm{P}_{5} \approx 40 \mathrm{kPa}$. Solid lines: present model; Dashed-dotted lines: Aramco 2.0; Dotted lines: CaltechMech; Dashed lines: JetSurf.

errors for quantity $Q$ are calculated using the following expression

$$
E_{\text {mean }}^{Q}=\frac{1}{N} \sum_{i}^{N}\left|\frac{\Delta Q}{Q_{\text {expe }}}\right|,
$$

where $\mathrm{N}$ is the number of data points, $\Delta Q=Q_{\text {model }}-Q_{\text {expe }}, Q_{\text {model }}$ and $Q_{\text {expe }}$ are the calculated and experimental characteristic quantities, respectively. The absolute values are used to avoid positive and negative errors to cancel out. Errors in the predictions of the four models are summarized in Table 2. Also reported are the errors of the present model without the vinyl alcohol sub-mechanism. Note that the experimental uncertainty for shock-tube data typically varies between 10 and $30 \%$ depending on the optical set-up and the chemical system [31, 94].

Figure 7 shows the predictions of the four models along with the experimental 
delay-times based on $\mathrm{OH}^{*}$ (present study); $\mathrm{CO}_{2} *([34]) ; \mathrm{OH}([36])$ and $\mathrm{O}_{2}([35])$. The present model predicts the delay-time based on $\mathrm{OH}^{*}, \mathrm{CH}^{*}$ and $\mathrm{CO}_{2}{ }^{*}$ emission within $45-60 \%$ on average whereas the other models over-estimate these data by at least 70\%. JetSurf demonstrates the highest disagreement with an average error on the order of $160-190 \%$. Better agreement is observed for delay-times based on $\mathrm{OH}$, $\mathrm{CO}_{2}$ and $\mathrm{O}_{2}$ with predictions within $67 \%$ for the four models. The present model is also better matching these latter data than the three other models with an average error below $22 \%$. Overall, the four models reproduce the activation energy observed experimentally.

\subsection{Species profiles}

Figure 8 shows typical comparisons between the experimental and calculated emission and species profiles from the present study and the literature [36, 40]. For the $\mathrm{OH}^{*}$ profiles (Figure 8 a)), the four models reproduce qualitatively the shape of the experimental profiles. CaltechMech is somewhat superior in reproducing the amplitude of the signal during the decaying period following the peak whereas Aramco overestimates this feature. The present model has an intermediate behavior. Concerning CO profiles (Figure 8 b)), the present model, Aramco and CaltechMech match quantitatively the profiles whereas JetSurf under-estimates the CO concentration. Figure $8 \mathrm{c}$ ) and d) show $\mathrm{OH} \mathrm{UV}$ absorption and $\mathrm{CO}_{2} \mathrm{IR}$ emission profiles as well as the calculated profiles. The four models reproduce qualitatively both experimental targets. The rate of $\mathrm{OH}$ radical consumption in $\mathrm{H}_{2}-\mathrm{O}_{2}$-Ar mixtures is overestimated by all models since the experimental profiles exhibit a plateau which is not captured. None of the models predict the UV absorption peak observed experimentally near time zero for mixture 14 . This could be attributed to $\mathrm{CH}_{3} \mathrm{CHO}$ since acetaldehyde exhibits a broad-band absorption feature between 230 and 340 nm [95]. This property was used by Wang et al. [37] who performed laser absorption measurements of $\mathrm{CH}_{3} \mathrm{CHO}$ under pyrolytic conditions at $306.7 \mathrm{~nm}$.

Figure 9 shows $\mathrm{H}$ atom profiles and the predictions of the models. Note that the data presented in Figure 9 a) have been obtained in a krypton bath and consequently, a collision efficiency of 0.93 has been included in all models based on Jasper et 


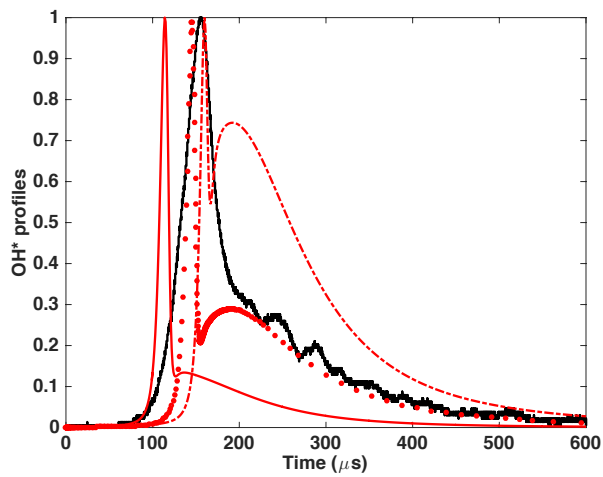

a) $\mathrm{OH}^{*}$ emission (Present study)

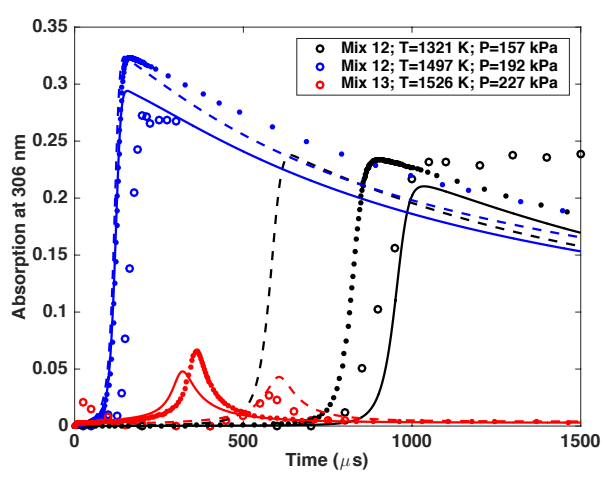

c) $\mathrm{OH}$ absorption $(306.7 \mathrm{~nm})[36]$

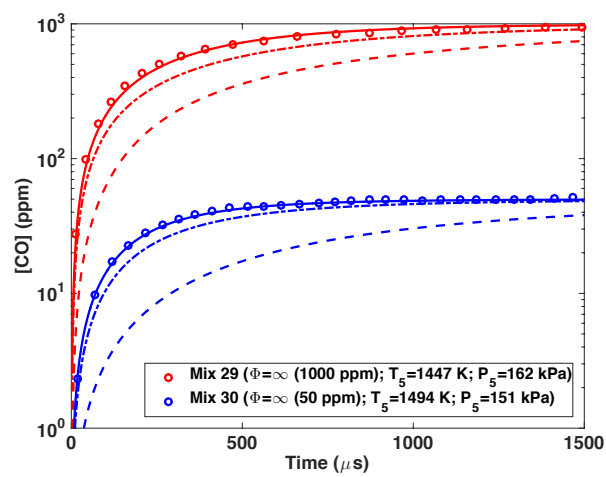

b) CO laser absorption $(4.6 \mu \mathrm{m})[40]$

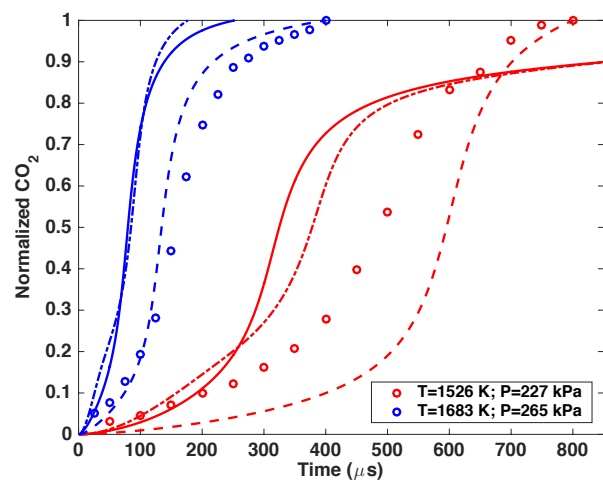

d) $\mathrm{CO}_{2}$ emission $(4.24 \mu \mathrm{m})[36]$

Figure 8: Comparison between the experimental and the predicted $\mathrm{OH}^{*}, \mathrm{CO}, \mathrm{OH}$ and $\mathrm{CO}_{2}$ profiles during the oxidation of $\mathrm{CH}_{3} \mathrm{CHO}$. In a): mixture $1\left(\Phi=0.5 ; \mathrm{X}_{A r}=0.97\right) ; \mathrm{T}_{5}=1506 \mathrm{~K} ; \mathrm{P}_{5}=339 \mathrm{kPa}$. In c): mixture $12\left(\mathrm{H}_{2}-\mathrm{O}_{2}-\mathrm{Ar} ; \Phi=0.5 ; \mathrm{X}_{A r}=0.98\right)$ and mixture $13\left(\mathrm{H}_{2}-\mathrm{O}_{2}-\mathrm{Ar}+1000 \mathrm{ppm} \mathrm{CH}_{3} \mathrm{CHO}\right.$; $\left.\Phi=0.5 ; \mathrm{X}_{A r}=0.98\right)$. In $\left.\mathrm{d}\right)$ : mixture $14\left(\Phi=2.5 ; \mathrm{X}_{A r}=0.96\right)$. Solid lines: present model; Dasheddotted lines: Aramco 2.0; Dotted lines: CaltechMech; Dashed lines: JetSurf.

al. study [74]. The present model, Aramco, and CaltechMech over-estimate the concentration of $\mathrm{H}$ atom in mixture 27 whereas JetSurf under-estimates it. For mixture 26, the present model, Aramco, and CaltechMech reproduce the $\mathrm{H}$ atom profile while JetSurf still under-estimates the experimental values. In Figure 9 b), the present model reproduces the shape and amplitude of the experimental profiles whereas the three other models predict lower $\mathrm{H}$ atom concentration. 


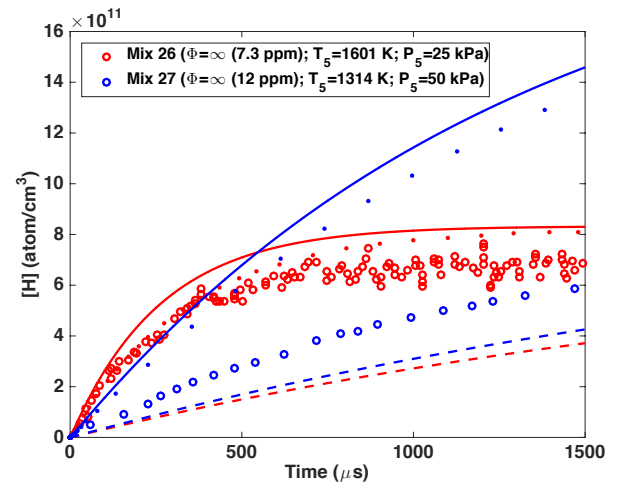

a) $\mathrm{CH}_{3} \mathrm{CHO}$ pyrolysis [39]

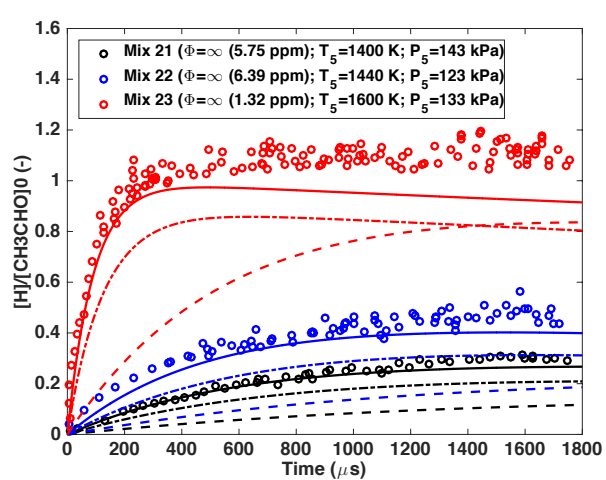

b) $\mathrm{CH}_{3} \mathrm{CHO}$ pyrolysis [38]

Figure 9: Comparison between the experimental and the predicted $\mathrm{H}$ atom profiles [38, 39] during the pyrolysis of $\mathrm{CH}_{3} \mathrm{CHO}-\mathrm{Ar}$ mixtures. Solid lines: present model; Dashed-dotted lines: Aramco 2.0; Dotted lines: CaltechMech; Dashed lines: JetSurf.

Figure 10 shows experimental and calculated temperature-resolved, Figure 10 a), and time-resolved, Figure $10 \mathrm{~b}$ ), species profiles for a variety of species. Overall, the present model and CaltechMech are superior in reproducing the experimental profiles since they qualitatively and quantitatively match the data for all the species. JetSurf tends to over-estimate the formation of $\mathrm{CH}_{4}$ and to under-estimate that of $\mathrm{C}_{2} \mathrm{H}_{4}$ and $\mathrm{C}_{2} \mathrm{H}_{2}$ in the high-temperature range whereas Aramco predicts a too low reactivity for the data shown in Figure 10 a).

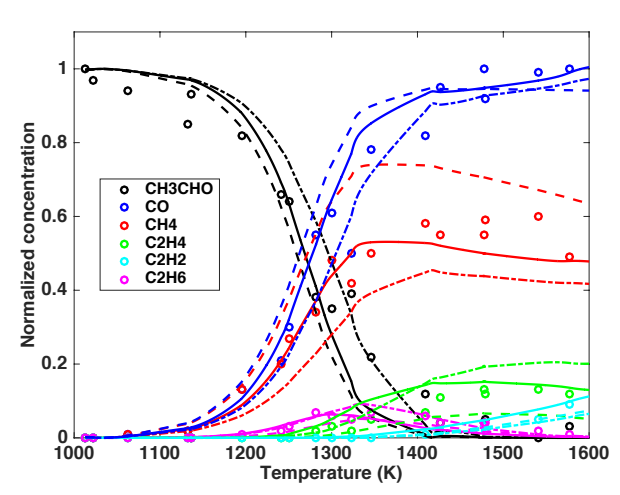

a) Sampling-GC analysis [36]

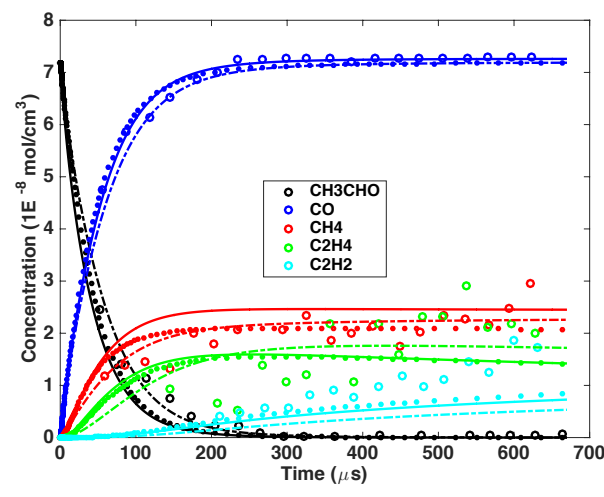

b) Time-resolved MS [30]

Figure 10: Comparison between the experimental and the predicted species profiles during the pyrolysis of $\mathrm{CH}_{3} \mathrm{CHO}-\mathrm{Ar}$ mixtures. In a): mixture $18\left(\Phi=\infty ; \mathrm{X}_{A r}=0.95 ; \mathrm{T}_{5}=1013-1577 \mathrm{~K} ; \mathrm{P}_{5}=128\right.$ $286 \mathrm{kPa})$. In b): mixture $25\left(\Phi=\infty ; \mathrm{X}_{A r}=0.968 ; \mathrm{T}_{5}=1717 \mathrm{~K} ; \mathrm{P}_{5}=32 \mathrm{kPa}\right)$. Solid lines: present model; Dashed-dotted lines: Aramco 2.0; Dotted lines: CaltechMech; Dashed lines: JetSurf. 


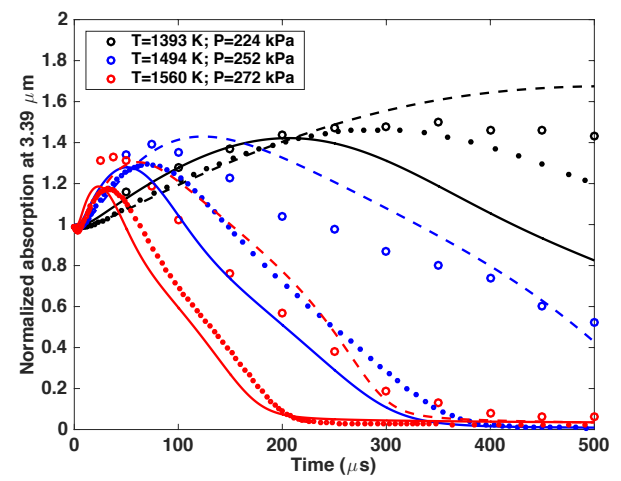

a) Absorption at $3.39 \mu \mathrm{m}$ for mixture 17

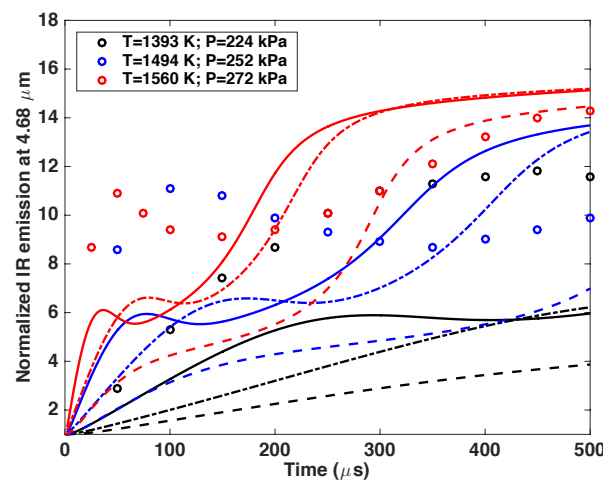

b) Emission at $4.68 \mu \mathrm{m}$ for mixture 17

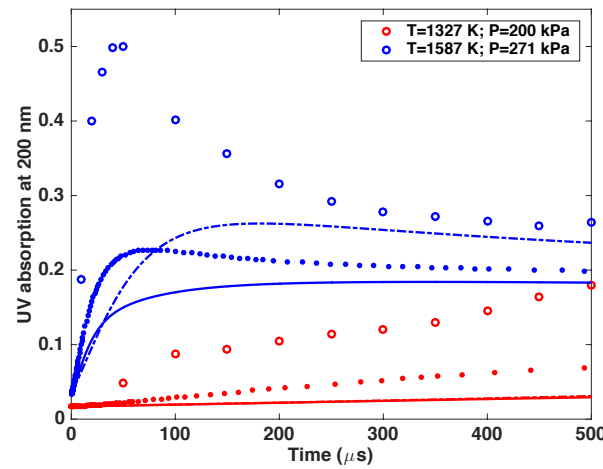

c) Absorption at $200 \mathrm{~nm}$ for mixture 19

Figure 11: Comparison between the experimental [36] and the predicted IR and UV absorption/emission profiles during the pyrolysis and oxidation of $\mathrm{CH}_{3} \mathrm{CHO}$. In a) and b): $\Phi=3.33$; $\mathrm{X}_{A r}=0.93$. In c): $\Phi=\infty ; \mathrm{X}_{A r}=0.99$. Solid lines: present model; Dashed-dotted lines: Aramco 2.0; Dotted lines: CaltechMech; Dashed lines: JetSurf.

Figure 11 shows typical comparisons between the experimental and calculated UV and IR absorption/emission profiles from [36] obtained under pyrolytic and oxidative conditions. All these profiles have been calculated according to the procedure mentioned in section 4 . For the IR absorption data $(3.39 \mu \mathrm{m})$ presented in 
Figure 11 a), JetSurf reproduces the profiles whereas the present model and CaltechMech tend to over-estimate the rate of $\mathrm{C}-\mathrm{H}$ bond removal in the high-temperature range. Aramco shows intermediate quantitative performances. Concerning IR emission profiles (Figure 11 b)), the present model, CaltechMech and Aramco capture the overall complex shape of the emission signals in the high-temperature range. JetSurf fails at reproducing the overall shape and significantly under-estimates the amplitude of the signals, by up to a factor of 3 . The shape of the profiles was attributed to the competition between $\mathrm{CH}_{2} \mathrm{CO}$ and $\mathrm{CO}$ emissions. The present model, Aramco, and CaltechMech predict a rapid formation of ketene at early times but not in a high enough quantity to reproduce the signals. JetSurf does not capture this feature. Finally, Figure 11 c) shows the experimental and calculated UV absorption profiles at $200 \mathrm{~nm}$ for pyrolytic conditions. The four reaction models fail in reproducing both the shape and the amplitude of the absorption signal. The low concentrations of ketene predicted by the models at early times explain the inconsistency in the calculated shape.

\section{Selected analyses}

A number of sensitivity analyses have been performed. Under pyrolytic conditions, mixture 18 has been used and a temperature of $1260 \mathrm{~K}$ has been selected because it corresponds approximately to the temperature at which $50 \%$ of $\mathrm{CH}_{3} \mathrm{CHO}$ is consumed in the experiments. Normalized sensitivity coefficients for $\mathrm{CH}_{3} \mathrm{CHO}$, $\mathrm{CO}$ and $\mathrm{CH}_{4}$, the three major species measured at the selected temperature, are shown in Figure 12. Under oxidative conditions, mixture 14 has been employed to investigate the effect of temperature, and mixtures 4 and 7 have been used to investigate the effect of pressure. Since $\Phi=2.5$ for mixture 14 and $\Phi=0.5$ for mixtures 4 and 7, the effect of equivalence ratio was also implicitly verified. Figure 13 and Figure 14 present the normalized sensitivity coefficients respectively for $\mathrm{CO}_{2}$ and $\mathrm{CO}_{2}{ }^{*}$. For each conditions, the 10 most sensitive reactions were extracted. For clarity, only the reactions demonstrating the highest sensitivity are shown.

Under pyrolytic conditions, see Figure 12, the chemical dynamics of the major species is dominated by the competition between reaction $\mathrm{R}_{1}: \mathrm{CH}_{3} \mathrm{CHO}(+\mathrm{M})=\mathrm{CH}_{3}+$ 

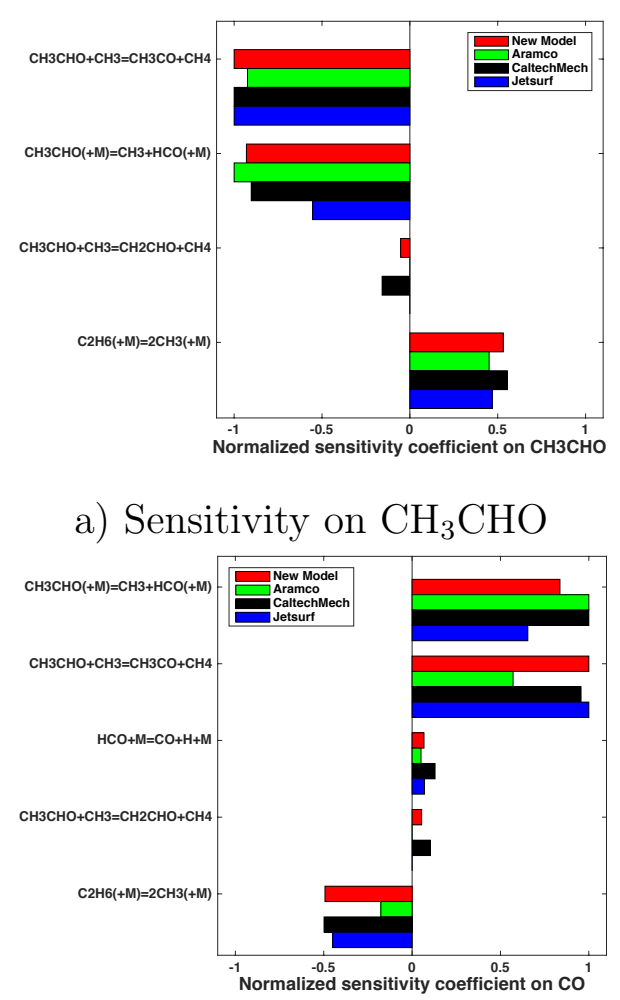

b) Sensitivity on $\mathrm{CO}$

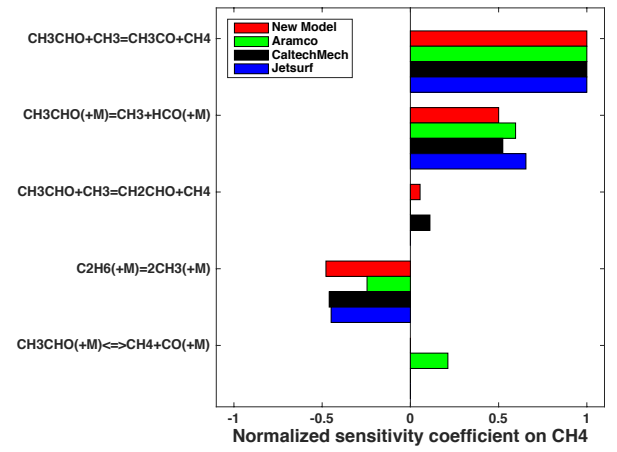

c) Sensitivity on $\mathrm{CH}_{4}$

Figure 12: Normalized sensitivity coefficients on $\mathrm{CH}_{3} \mathrm{CHO}, \mathrm{CO}$ and $\mathrm{CH}_{4}$ during the pyrolysis of acetaldehyde. In a), b) and c): mixture $18\left(\Phi=\infty ; \mathrm{X}_{A r}=0.95\right) ; \mathrm{T}=1260 \mathrm{~K} ; \mathrm{P}=202 \mathrm{kPa}$.

$\mathrm{HCO}(+\mathrm{M})$ and reaction $\mathrm{R}_{2}: \mathrm{CH}_{3} \mathrm{CHO}+\mathrm{CH}_{3}=\mathrm{CH}_{3} \mathrm{CO}+\mathrm{CH}_{4}$. Reaction $\mathrm{R}_{3}: \mathrm{CH}_{3} \mathrm{CHO}$ $+\mathrm{CH}_{3}=\mathrm{CH}_{2} \mathrm{CHO}+\mathrm{CH}_{4}$ appears among the 10 most sensitive reactions but with much lower coefficients than $R_{1}$ and $R_{2}$. The decomposition of ethane (or recombination of methyl radical) $\mathrm{C}_{2} \mathrm{H}_{6}(+\mathrm{M})=\mathrm{CH}_{3}+\mathrm{CH}_{3}(+\mathrm{M})$ is the third most sensitive reaction with coefficients of the opposite sign as compared to $R_{1}$ and $R_{2}$.

Under oxidative conditions, see Figure 13 and Figure 14, the chain branching 

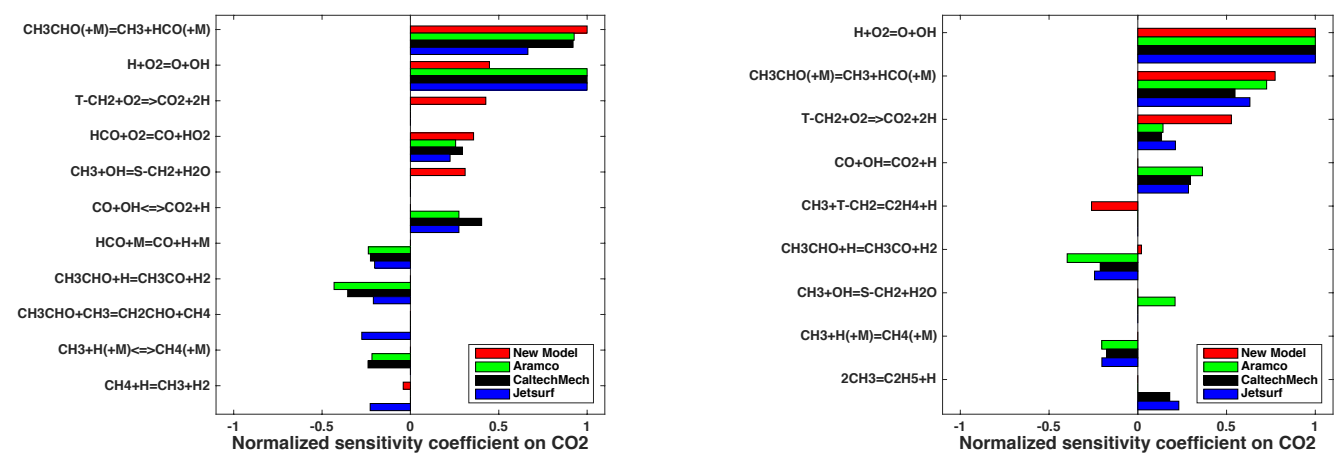

a) Mixture 14; $\mathrm{T}=1400 \mathrm{~K} ; \mathrm{P}=202 \mathrm{kPa} \quad$ b) Mixture 14; $\mathrm{T}=1700 \mathrm{~K} ; \mathrm{P}=202 \mathrm{kPa}$

Figure 13: Normalized sensitivity coefficients on $\mathrm{CO}_{2}$ during the oxidation of acetaldehyde. In a) and b): $\Phi=2.5 ; \mathrm{X}_{A r}=0.96$.

reaction $\mathrm{H}+\mathrm{O}_{2}=\mathrm{OH}+\mathrm{O}$ is in most cases as or more sensitive than $\mathrm{R}_{1}$ for $\mathrm{CO}_{2}$ (one of the main combustion product) and $\mathrm{CO}_{2}{ }^{*}$ (ignition marker). As the temperature or the pressure increases, the sensitivity coefficient of the chain branching reaction increases whereas the coefficient of $\mathrm{R}_{1}$ is decreasing. For all the conditions used to obtain Figure 13 and Figure 14, the reaction $\mathrm{R}_{4}$ : $\mathrm{CH}_{3} \mathrm{CHO}+\mathrm{H}=\mathrm{CH}_{3} \mathrm{CO}+\mathrm{H}_{2}$ exhibits the highest negative sensitivity coefficient. As seen for pyrolytic conditions, the reaction $\mathrm{C}_{2} \mathrm{H}_{6}(+\mathrm{M})=\mathrm{CH}_{3}+\mathrm{CH}_{3}(+\mathrm{M})$ is important for $\mathrm{CH}_{3} \mathrm{CHO}$ oxidation and reduce the reactivity of the mixture. Overall, these results are consistent with the preliminary analyses shown in section 4 and further justify the choice of the reactions for which we performed a rate constant update.
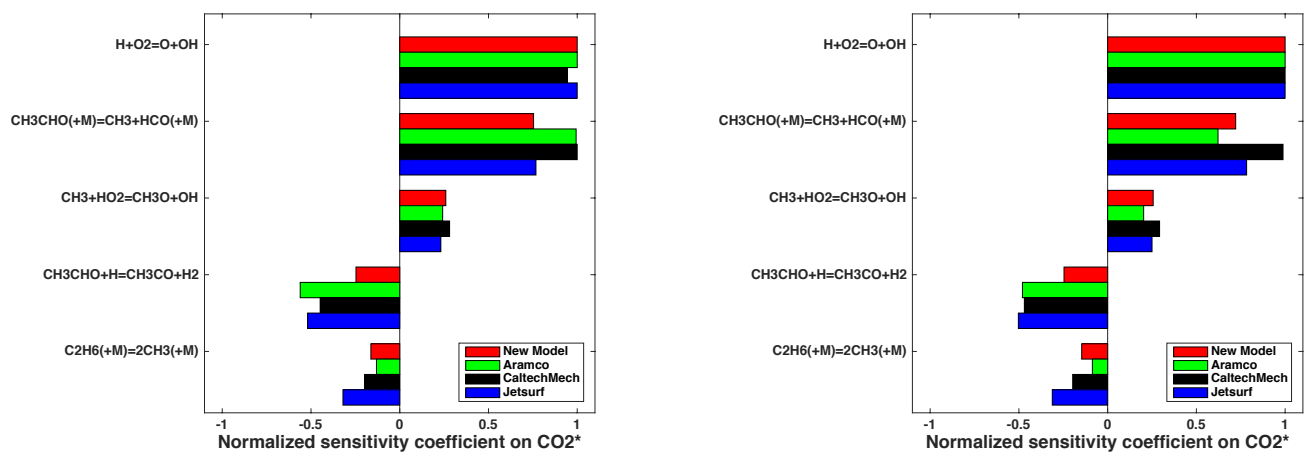

a) Mixture 4; $\mathrm{T}=1380 \mathrm{~K} ; \mathrm{P}=353 \mathrm{kPa} \quad$ b) Mixture 7; $\mathrm{T}=1380 \mathrm{~K} ; \mathrm{P}=507 \mathrm{kPa}$

Figure 14: Normalized sensitivity coefficients on $\mathrm{CO}_{2}{ }^{*}$ during the oxidation of acetaldehyde. In a): $\Phi=0.5 ; \mathrm{X}_{A r}=0.97$. In b): $\Phi=0.5 ; \mathrm{X}_{A r}=0.97$. 


\section{Summary and discussion on the models performance}

From the comprehensive modeling study presently performed, a number of conclusions can be drawn concerning the performances of the reaction models. It can be pointed out that all the reaction models predict better the characteristic times of reaction based on $\mathrm{OH}, \mathrm{O}_{2}$, and $\mathrm{CO}_{2}$ than those based on electronically excited species, $\mathrm{OH}^{*}, \mathrm{CH}^{*}$, and $\mathrm{CO}_{2}{ }^{*}$. Under pyrolytic conditions, the models predict qualitatively and quantitatively most of the emission and species profiles. The largest discrepancies are observed for the hydrogen atom profiles and the emission and absorption profiles which are influenced by a rapid production of ketene at early time. Under oxidative conditions, the models reproduce the $\mathrm{OH}, \mathrm{CO}_{2}$, and $\mathrm{CO}_{2}{ }^{*}$ profiles. The $\mathrm{CH}^{*}$ profiles are systematically predicted much narrower than observed experimentally. The IR and UV absorption profiles are reproduced well by some models but not by others. Overall, the present model performs better than the three others especially for the delay-times whatever species is used to obtained them. JetSurf demonstrates the least satisfactory performances. This is reflected by the underestimation of the reactivity of the mixtures which results in too long delay-time and species profiles often off.

Since the rate constants included in the four models for the branching reaction $\mathrm{H}+\mathrm{O}_{2}=\mathrm{OH}+\mathrm{O}$ are equivalent (Aramco, CaltechMech and the present model employ the rate constant from Hong et al. [69] whereas JetSurf employs the GRI-Mech 3.0 value, which is within $5 \%$ of Hong's value over the temperature range 1000$2000 \mathrm{~K}$ ), the differences between the predictions of the four reaction models are essentially explained by the difference in the rate constant used for $R_{1}$. As shown in subsection 5.1, the presently proposed rate constant demonstrates lower error with respect to the experimental data from $[38,40,65,73]$ than the rate constants included in the other reaction models. The inclusion of the new rate constant for $\mathrm{R}_{1}$ constitutes the main improvement brought to the present reaction model and it was verified that it enables to significantly improve the predictive capability of the three other models. The inclusion of the rate constant from Mendes [78] for the reactions $\mathrm{CH}_{3} \mathrm{CHO}+\mathrm{H}$ and $\mathrm{CH}_{3} \mathrm{CHO}+\mathrm{CH}_{3}$ enabled to give a consistent picture of these pathways. However, the accuracy for these rates is limited (factor of 2.5) 
which makes the branching ratios quite uncertain. More accurate measurements or calculations would be needed to further improve the modeling of acetaldehyde pyrolysis and oxidation.

\section{Conclusion}

In the present study, new shock-tube experiments for $\mathrm{CH}_{3} \mathrm{CHO}-\mathrm{O}_{2}-\mathrm{Ar}$ mixtures have been performed and an updated detailed reaction model for high-temperature acetaldehyde pyrolysis and oxidation has been developed and validated against a comprehensive shock-tube experimental database. The present model is compared to three other well-known detailed chemical models: Aramco 2.0, CaltechMech, and JetSurf. Overall, the present model demonstrates better performance than the three other models especially in reproducing the characteristic time of reaction based on $\mathrm{OH}^{*}, \mathrm{CH}^{*}, \mathrm{CO}_{2}{ }^{*}, \mathrm{CO}_{2}$ emission, $\mathrm{OH}$ absorption and $\mathrm{O}_{2}$ profiles. In addition, the present model reproduces most of the trends observed experimentally for numerous temperature or time resolved profiles, including $\mathrm{OH}^{*}, \mathrm{CH}^{*}, \mathrm{CO}_{2}{ }^{*}$, $\mathrm{CO}_{2}, \mathrm{O}_{2}, \mathrm{OH}, \mathrm{H}, \mathrm{CH}_{3} \mathrm{CHO}, \mathrm{CO}, \mathrm{CH}_{4}, \mathrm{C}_{2} \mathrm{H}_{6}, \mathrm{C}_{2} \mathrm{H}_{4}, \mathrm{C}_{2} \mathrm{H}_{2}$, IR emission and UV absorption. Aramco and CaltechMech perform significantly better than JetSurf for most of the conditions presently investigated. The difference between the reaction models peformance is primarily due to the value of the rate constant used for the decomposition of acetaldehyde. Using a large set of rate constant measurements from the literature, an updated rate constant for this reaction has been obtained and would enable improving the predictive capability of the three models from the literature. Consistent with the results of Yasunaga et al. [36], the early formation of ketene, $\mathrm{CH}_{2} \mathrm{CO}$, was found to be important to reproduce the shape of some timeresolved UV absorption and IR emission profiles. Specific measurements of ketene during acetaldehyde oxidation, such as those from Tao et al. [27], would be useful to improving detailed reaction models. The inclusion of the vinyl alcohol formation pathways from Sivaramakrishnan et al. [23] does not significantly influence the predictions of the present model in terms of ignition delay-time. This is because the experiments of Vasiliou et al. [28, 29], which enabled the identification of vinyl alcohol as one of the primary chemical species during acetaldehyde pyrolysis, were 
performed under conditions which are essentially of little to no relevance to most combustion applications. Despite the large database assembled, we note that, to the best of our knowledge, the experimental investigation of acetaldehyde hightemperature kinetics has been essentially limited to low pressures, below $500 \mathrm{kPa}$. Improving acetaldehyde chemical kinetics under gas turbine and internal combustion engine conditions requires experimental studies performed at much higher pressures.

\section{Acknowledgments}

Karl Chatelain was supported by the "Conseil Régional du Centre" during his stay at Caltech. Discussions with Dr F. Bernard (NOAA Boulder) and Dr P. Boettcher (Boeing) are greatly appreciated. The authors are grateful to Dr R. Sivaramakrishnan (Argonne National Laboratory) for providing the reaction rates and thermodynamic data for the vinyl alcohol sub-mechanism. The authors would like to thank Pr G. Dayma (University of Orléans), Pr A. Konnov (Lund University), and Pr B. Yang (Tsinghua University), for providing respectively the JSR, flame speed, and flat burner data shown as supplemental material. 


\section{References}

[1] Directive 2009/28/ec of the european parliament and of the council of 23 april 2009 on the promotion of the use of energy from renewable sources and amending and subsequently repealing directives 2001/77/ec and 2003/30/ec, 2009.

[2] J. Zhang, L. Pan, J. Mo, J. Gong, Z. Huang, C. K. Law, Combustion and Flame 160 (2013) 1541-1549.

[3] F. Posada, C. Malins, A. Baral, Biodiesel carbon intensity, sustainability and effects on vehicles and emissions, Technical Report, Technical report, The International Council on Clean Transportation, 2012.

[4] S. Van Renssen, Nature Climate Change 1 (2011) 389-390.

[5] Z. Habib, R. Parthasarathy, S. Gollahalli, Applied Energy 87 (2010) 1701-1709.

[6] M. Ditaranto, H. Li, Y. Hu, Energy Procedia 63 (2014) 1972-1975.

[7] R. Edwards, J.-F. Larivé, V. Mahieu, P. Rouveirolles, et al., CONCAWE, European Council for Automotive R\&D, JRC Joint Research Centre of the European Commission, Version 2c (2007).

[8] L. L. N. Guarieiro, A. F. de Souza, E. A. Torres, J. B. de Andrade, Atmospheric Environment 43 (2009) 2754-2761.

[9] G. da Silva, J. Bozzelli, The Journal of Physical Chemistry A 110 (2006) 1305813067.

[10] P. S. Veloo, P. Dagaut, C. Togbé, G. Dayma, S. M. Sarathy, C. K. Westbrook, F. N. Egolfopoulos, Combustion and Flame 160 (2013) 1609-1626.

[11] G. Fontaras, G. Karavalakis, M. Kousoulidou, L. Ntziachristos, E. Bakeas, S. Stournas, Z. Samaras, Environmental Pollution 158 (2010) 2496-2503.

[12] O. E. Company, E20 Vehicle Ethanol Report, Technical Report, Orbital Engine Company, 2003. 
[13] C. P. Hubbard, J. E. Anderson, T. J. Wallington, Environmental science \& technology 48 (2013) 861-867.

[14] P. A. Stansfield, A. Bisordi, D. OudeNijeweme, J. Williams, M. Gold, R. Ali, SAE International Journal of Fuels and Lubricants 5 (2012) 813-822.

[15] Carb, 2012. final regulation order, lev iii amendments, california code of regulations, title 13, sections 1900, 1956.8, 1960.1, 1961, 1961.2, 1961.3, 1962.1, 1962.2, and 1976, as amended: December 6, 2012.

[16] Epa, 2013. "tier 3 vehicle emission and fuel standards program", internet; accessed on may 8, 2013

[17] B. Akih-Kumgeh, J. M. Bergthorson, Combustion and Flame 158 (2011) 18771889.

[18] C. He, Y. Ge, J.Tan, K. You, X. Han, J. Wang, Q. You, A. Shah, Atmospheric Environment 43 (2009) 3657 - 3661.

[19] O. Faroon, N. Roney, J. Taylor, A. Ashizawa, M. Lumpkin, D. Plewak, Toxicology and Industrial Health 24 (2008) 447-490.

[20] J. Yanowitz, K. Knoll, J. Kemper, J. Luecke, R. L. McCormick, Environmental science \& technology 47 (2013) 2990-2997.

[21] B. W. LaFranchi, G. M. Wolfe, J. A. Thornton, S. A. Harrold, E. C. Browne, K. E. Min, P. J. Wooldridge, J. B. Gilman, W. C. Kuster, P. D. Goldan, J. A. de Gouw, M. McKay, A. H. Goldstein, X. Ren, J. Mao, R. C. Cohen, Atmospheric Chemistry and Physics 9 (2009) 7623-7641.

[22] E. V. Fischer, D. J. Jacob, R. M. Yantosca, M. P. Sulprizio, D. B. Millet, J. Mao, F. Paulot, H. B. Singh, A. Roiger, L. Ries, R. W. Talbot, K. Dzepina, S. Pandey Deolal, Atmospheric Chemistry and Physics 14 (2014) 2679-2698.

[23] R. Sivaramakrishnan, J. Michael, L. Harding, S. Klippenstein, Journal of Physical Chemistry A 119 (2015) 7724-7733. 
[24] Y. Li, C.-W. Zhou, K. Somers, K. Zhang, H. Curran, Proceedings of the Combustion Institute 36 (2017) 403-411.

[25] W. Metcalfe, S. Burke, S. Ahmed, C. H.J., International Journal of Chemical Kinetics 45 (2013) 638-675.

[26] G. Blanquart, P. Pepiot-Desjardins, H. Pitsch, Combustion and Flame 156 (2009) 588-607.

[27] T. Tao, W. Sun, B. Yang, N. Hansen, K. Moshammer, C. Law, Proceedings of the Combustion Institute In press (2016).

[28] A. Vasiliou, K. Piech, X. Zhang, M. Nimlos, M. Ahmed, A. Golan, O. Kostko, D. Osborn, J. Daily, J. Stanton, B. E.G., The Journal of Chemical Physics 135 (2011) 014306.

[29] A. Vasiliou, K. Piech, B. Reed, X. Zhang, M. Nimlos, M. Ahmed, A. Golan, O. Kostko, D. Osborn, D. David, K. Urness, J. Daily, J. Stanton, G. B. Ellison, The Journal of Chemical Physics 137 (2012) 164308.

[30] R. Kern, H. Singh, K. Xie, AIP Conference Proceedings 208 (1990) 487-492.

[31] R. Mével, S. Pichon, L. Catoire, N. Chaumeix, C. E. Paillard, J. E. Shepherd, Proceedings of the Combustion Institute 34 (2013) 677-684.

[32] R. Mével, J. E. Shepherd, Shock Waves 25 (2015) 217-229.

[33] K. Chatelain, R. Mével, S. Menon, G. Blanquart, J. Shepherd, Fuel 135 (2014) $498-508$.

[34] P. Dagaut, M. Reuillon, D. Voisin, M. Cathonnet, M. M. Guinness, J. Simmie, Combustion Science and Technology 107 (1995) 301-316.

[35] Y. Hidaka, M. Suga, Journal of the Mass Spectrometry Society of Japan 35 (1987) 74-83.

[36] K. Yasunaga, S. Kubo, H. Hoshikawa, T. Kamesawa, Y. Hidaka, International Journal of Chemical Kinetics 40 (2008) 73-102. 
[37] S. Wang, D. Davidson, R. Hanson, Combustion and Flame 160 (2013) 19301938.

[38] T. Bentz, F. Striebel, , M. Olzmann, Journal of Physical Chemistry A 112 (2008) 6120-6124.

[39] R. Sivaramakrishnan, J. V. Michael, S. J. Klippenstein, The Journal of Physical Chemistry A 114 (2010) 755-764.

[40] S. Wang, D. Davidson, R. Hanson, Journal of Physical Chemistry A In press (2016).

[41] N. Lamoureux, C.-E. Paillard, V. Vaslier, Shock Waves 11 (2002) 309-322.

[42] D. Horning, D. Davidson, R. Hanson, Journal of propulsion and Power 18 (2002) 363-371.

[43] B. Rotavera, P. Dievart, C. Togbe, P. Dagaut, E. Petersen, Proceedings of the Combustion Institute 33 (2011) 175-183.

[44] D. Kalitan, J. Hall, E. Petersen, Journal of Propulsion and Power 21 (2005) 1045-1056.

[45] J. Zhang, L. Pan, J. Mo, J. Gong, Z. Huang, C. Law, Combustion and Flame 160 (2013) $1541-1549$.

[46] D. Davidson, S. Ranganath, K.-Y. Lam, M. Liaw, Z. Hong, R. Hanson, Journal of Propulsion and Power 26 (2010) 280-287.

[47] N. Lamoureux, C.-E. Paillard, Shock Waves 13 (2003) 57-68.

[48] P. Beeley, J. Griffiths, B. Hunt, A. Williams, Symposium (International) on Combustion 16 (1977) $1013-1022$.

[49] S.-J. Won, J.-C. Ryu, J.-H. Bae, K. Y.-D., J.-G. Kang, Bulletin of the Korean Chemical Society 21 (2000) 487-492.

[50] F. Rice, R. Varnerin, Journal of the American Chemical Society 77 (1955) 221224. 
[51] N. Imai, O. Toyama, Bulletin of the Chemical Society of Japan 33 (1960) 14081412 .

[52] I. Bardi, T. Berces, I. Szilagyi, International Journal of Chemical Kinetics 8 (1976) 285-294.

[53] R. Brinton, D. Volman, The Journal of Chemical Physics 20 (1952) 1053-1054.

[54] R. E. Dodd, Canadian Journal of Chemistry 33 (1955) 699-704.

[55] R. N. Birrell, A. F. Trotman-Dickenson, Journal of the Chemical Society (1960) 2059-2063.

[56] J. Kerr, J. Calvert, The Journal of Physical Chemistry 69 (1965) 1022-1029.

[57] M. Liu, K. Laidler, Canadian Journal of Chemistry 46 (1968) 479-490.

[58] M. Colket, D. Naegeli, I. Glassman, Symposium (International) on Combustion 16 (1977) $1023-1039$.

[59] K. Laidler, M. Liu, Proceedings of the Royal Society of London A: Mathematical, Physical and Engineering Sciences 297 (1967) 365-375.

[60] D. Volman, R. Brinton, The Journal of Chemical Physics 20 (1952) 1764-1768.

[61] R. E. Dodd, Transactions of the Faraday Society 47 (1951) 56-62.

[62] R. Baldwin, D. Langford, M. Matchan, R. Walker, D. Yorke, Symposium (International) on Combustion 13 (1971) 251 - 259.

[63] T. Bell, K. Kutschke, Canadian Journal of Chemistry 42 (1964) 2713-2720.

[64] P. Ausloos, E. W. R. Steacie, Canadian Journal of Chemistry 33 (1955) 31-38.

[65] J. Ernst, K. Spindler, H. G. Wagner, Berichte der Bunsengesellschaft fur physikalische Chemie 80 (1976) 645-650.

[66] M. B. Colket, D. W. Naegeli, I. Glassman, International Journal of Chemical Kinetics 7 (1975) 223-247. 
[67] R. Mével, K. Chatelain, L. Catoire, W. Green, J. Shepherd, Proceedings of the 9th Joint US Sections Meeting of the Combustion Institute, 2015 (2015) Paper \# 114RK-0165.

[68] L. S. Rothman, A. Barbe, D. C. Benner, L. R. Brown, C. Camy-Peyret, M. R. Carleer, K. Chance, C. Clerbaux, V. Dana, V. M. Devi, A. Fayt, J. M. Flaud, R. R. Gamache, A. Goldman, D. Jacquemart, K. W. Jucks, W. J. Lafferty, J. Y. Mandin, S. T. Massie, V. Nemtchinov, D. A. Newnham, A. Perrin, C. P. Rinsland, J. Schroeder, K. M. Smith, M. A. H. Smith, K. Tang, R. A. Toth, J. Vander Auwera, P. Varanasi, K. Yoshino, Journal of Quantitative Spectroscopy and Radiative Transfer 82 (2003) 5-44.

[69] Z. Hong, D. Davidson, E. Barbour, R. Hanson, Proceedings of the Combustion Institute 33 (2011) $309-316$.

[70] Z. Hong, An improved hydrogen/oxygen mechanism based on shock tube/laser absorption measurements, Ph.D. thesis, Stanford University, 2010.

[71] D. L. Baulch, C. T. Bowman, C. J. Cobos, R. A. Cox, T. Just, J. A. Kerr, M. J. Pilling, D. Stocker, J. Troe, W. Tsang, R. W. Walker, J. Warnatz, Journal of Physical and Chemical Reference Data 34 (2005) 757-1397.

[72] R. Mével, S. Javoy, K. Coudoro, G. Dupré, C. E. Paillard, International Journal of Hydrogen Energy 37 (2012) 698-714.

[73] K. Gupte, J. Kiefer, R. Tranter, S. Klippenstein, L. Harding, Proceedings of the Combustion Institute 31 (2007) 167-174.

[74] A. Jasper, C. Oana, J. Miller, Proceedings of the Combustion Institute 35 (2015).

[75] L. Harding, Y. Georgievskii, S. Klippenstein, Journal of Physical Chemistry A 114 (2010) 765-777.

[76] J. Troe, Combustion and Flame 158 (2011) 594 - 601. Special Issue on Kinetics. 
[77] B. Sirjean, E. Dames, D. A. Sheen, X.-Q. You, C. Sung, A. T. Holley, F. N. Egolfopoulos, H. Wang, S. S. Vasu, D. F. Davidson, R. K. Hanson, H. Pitsch, C. T. Bowman, A. Kelley, C. K. Law, W. Tsang, N. P. Cernansky, D. L. Miller, A. Violi, R. P. Lindstedt, A high-temperature chemical kinetic model of n-alkane oxidation, jetsurf version 0.2 , Available at: http : //melchior.usc.edu/JetSurF/Version $0_{2} /$ Index.html, 2008.

[78] J. Mendes, C.-W. Zhou, H. Curran, Journal of Physical Chemistry A 118 (2014) 12089-12104.

[79] J. Senosiain, S. Klippenstein, J. Miller, Journal of Physical Chemistry A 110 (2006) 5772-5781.

[80] A. Konnov, Detailed reaction mechanism for small hydrocarbons combustion. release 0.5., 2000 .

[81] T. Le Cong, P. Dagaut, Proc. Combust. Inst. 32 (2009) 427-435.

[82] T. Le Cong, Etude expérimentale et modélisation de la cinétique de combustion de combustibles gazeux : Méthane, gaz naturel et mélanges contenant de l'hydrogène, du monoxyde de carbone, du dioxyde de carbone et de l'eau, Ph.D. thesis, Université d'Orléans, 2007.

[83] E. Greenwald, S. North, Y. Georgievskii, S. Klippenstein, The Journal of Physical Chemistry A 109 (2005) 6031-6044.

[84] X. You, H. Wang, E. Goos, C.-J. Sung, S. Klippenstein, The Journal of Physical Chemistry A 111 (2007) 4031-4042.

[85] M. Kopp, O. Mathieu, E. Petersen, International Journal of Chemical Kinetics 47 (2015) 50-72.

[86] S. Kumaran, M.-C. Su, K. Lim, J. Michael, Symposium (International) on Combustion 26 (1996) 605-611.

[87] S. Kumaran, M.-C. Su, J. Michael, International Journal of Chemical Kinetics 29 (1997) 535-543. 
[88] T. Bentz, M. Szori, B. Viskolcz, M. Olzmann, Zeitschrift f,r Physikalische Chemie International journal of research in physical chemistry and chemical physics 225 (2011) 1117-1128.

[89] J. Knox, R. Musgrave, Transactions of the Faraday Society 63 (1967) 22012216.

[90] A. Lifshitz, C. Tamburu, , F. Dubnikova, The Journal of Physical Chemistry A 112 (2008) 925-933.

[91] S. Pardini, D. Martin, International Journal of Chemical Kinetics 15 (1983) 1031-1043.

[92] D. Baulch, J. Duxbury, S. Grant, D. Montague, Journal of Physical and Chemical Reference Data 10 (1981).

[93] M. Allendorf, F. Maury, and F. Teyssandier (Ed.), D. G. Goodwin, in Chemical Vapor Depostion XVI and EUROCVD 14, Electrochemical Society Proceedings Series, Pennington, NJ, p. 155.

[94] O. Mathieu, B. Giri, A. Agard, T. Adams, J. Mertens, E. Petersen, Fuel 182 (2016) 597-612.

[95] P. Limao-Vieira, S. Eden, N. Mason, S. Hoffmann, Chemical Physics Letters 376 (2003) 737-747. 